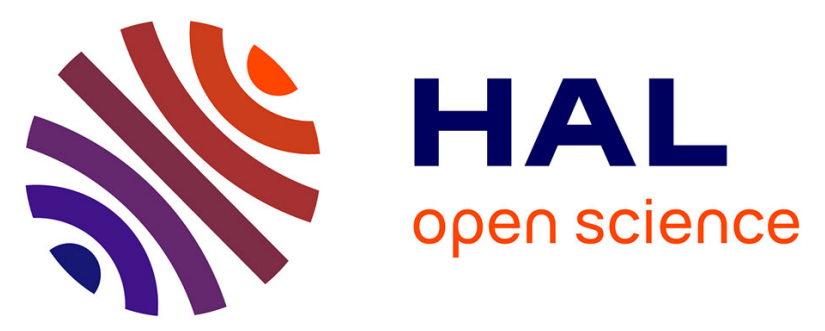

\title{
Development of a synthetic single crystal diamond dosimeter for dose measurement of clinical proton beams
}

Cyril Moignier, Dominique Tromson, Ludovic de Marzi, Fanny Marsolat, Juan

Carlos García Hernández, Mathieu Agelou, Michal Pomorski, Romuald Woo, Jean-Michel Bourbotte, Fabien Moignau, et al.

\section{To cite this version:}

Cyril Moignier, Dominique Tromson, Ludovic de Marzi, Fanny Marsolat, Juan Carlos García Hernández, et al.. Development of a synthetic single crystal diamond dosimeter for dose measurement of clinical proton beams. Physics in Medicine and Biology, 2017, 62 (13), pp.5417 - 5439. 10.1088/13616560/aa70cf . hal-01880969

\section{HAL Id: hal-01880969 \\ https://hal.science/hal-01880969}

Submitted on 10 May 2019

HAL is a multi-disciplinary open access archive for the deposit and dissemination of scientific research documents, whether they are published or not. The documents may come from teaching and research institutions in France or abroad, or from public or private research centers.
L'archive ouverte pluridisciplinaire HAL, est destinée au dépôt et à la diffusion de documents scientifiques de niveau recherche, publiés ou non, émanant des établissements d'enseignement et de recherche français ou étrangers, des laboratoires publics ou privés. 


\section{Development of a synthetic single crystal diamond dosimeter for dose measurement of clinical proton beams}

Running head: Single crystal diamond dosimeter for clinical proton beams

5

\section{Author list:}

Cyril Moignier ${ }^{1,2}$, Dominique Tromson ${ }^{3}$, Ludovic de Marzi ${ }^{2}$, Fanny Marsolat ${ }^{2}$, Juan Carlos García Hernández ${ }^{1}$, Mathieu Agelou ${ }^{1}$, Michal Pomorski ${ }^{4}$, Romuald Woo $^{3}$, Jean-Michel Bourbotte ${ }^{3}$, Fabien Moignau $^{5}$, Delphine Lazaro ${ }^{1}$, Alejandro Mazal ${ }^{2}$

10

${ }^{1}$ CEA, LIST, System Modelling and Simulation Laboratory, 91191 Gif-sur-Yvette, France

${ }^{2}$ Institut Curie, Centre de Protonthérapie d'Orsay, 91400 Orsay, France

${ }^{3}$ CEA, LIST, Sensors and Electronic Architectures Laboratory, 91191 Gif-sur-Yvette, France

${ }^{4}$ CEA, LIST, Diamond Sensors Laboratory, 91191 Gif-sur-Yvette, France

${ }^{5}$ CEA, LIST, Henri Becquerel National Laboratory, 91191 Gif-sur-Yvette, France

Email of corresponding author: cyril.moignier@free.fr

\section{$\underline{\text { Abstract: }}$}

The scope of this work was to develop a synthetic single crystal diamond dosimeter (SCDD-Pro) for accurate relative dose measurements of clinical proton beams in water. Monte Carlo simulations were carried out based on the MCNPX code in order to investigate and reduce the dose curve perturbation caused by the SCDD-Pro. In particular, various diamond thicknesses were simulated to evaluate the influence of the active volume thickness $\left(\mathrm{e}_{\mathrm{AV}}\right)$ as well as the influence of the addition of a front silver resin $(250 \mu \mathrm{m}$ in thickness in front of the diamond crystal) on depth-dose curves. The simulations indicated that the diamond crystal alone, with a small $\mathrm{e}_{\mathrm{AV}}$ of just $5 \mu \mathrm{m}$, already affects the dose at Bragg peak position (Bragg peak dose) by more than 2\% with respect to the Bragg peak dose deposited in water. The optimal design that resulted from the Monte Carlo simulations consists of a diamond crystal of $1 \mathrm{~mm}$ in width and $150 \mu \mathrm{m}$ in thickness with the front silver resin, enclosed by a water-equivalent packaging. This design leads to a deviation between the Bragg peak dose from the full detector modeling and the Bragg peak dose deposited in water of less than 1.2\%. Based on those optimizations, an SCDD-Pro prototype was built and evaluated in broad passive scattering proton beams. The experimental evaluation led to probed SCDD-Pro repeatability, dose rate dependence and 
linearity, that were better than $0.2 \%, 0.4 \%$ (in the 1.0 to $5.5 \mathrm{~Gy} / \mathrm{min}$ range) and $0.4 \%$ (for dose higher than 0.05 Gy), respectively. The depth-dose curves in the 90-160 MeV energy range, measured with the SCDD-Pro without applying any correction, were in good agreement with those measured using a commercial IBA PPC05 plane-parallel ionization chamber, differing by less than $1.6 \%$. The experimental results confirmed that this SCDD-Pro is suitable for measurements with standard electrometers and that the depth-dose curve perturbation is negligible, with no energy dependence and no significant dose rate dependence.

\section{Keywords:} proton therapy, diamond dosimeter, design optimization, dose perturbation, depth-dose curve. 


\section{INTRODUCTION}

Proton therapy is an advanced radiotherapy approach that enables clinicians to closely conform the dose to the target tissues while limiting surrounding tissue exposure. Three delivery techniques are currently used: passive scattering, uniform scanning and pencil beam scanning. The passive scattering technique consists of spreading the beam by interposing scattering elements in the beam line. The resulting broad beam is conformed to the target laterally using collimators. A range shifter, range modulator wheel, and compensators are used to conform the dose to the distal edge of the target. The uniform scanning technique consists of a single scattering element with steering magnets to produce uniform dose laterally. The pencil beam scanning technique was first used with protons for treating deep-seated tumors in 1992 at the Paul Scherrer Institute in Switzerland. The pencil beam is magnetically deflected in order to scan the target volume (Pedroni et al 1995), improving the quality of the dose distributions. Accurate proton pencil beam dosimetry requires special precautions due to the small size of the beam, the pulsed high dose rate and the proton energy variation with depth in water. Another problem is finding high spatial resolution detectors appropriate for measurements in narrow proton beams, because such detectors typically have energy, dose rate and linear energy transfer (LET) dependences (Vatnitsky et al 1999, Karger et al 2010).

Because of their high spatial resolution and high sensitivity, solid state detectors are widely used for relative photon and electron beam dose measurements with strong dose gradients. However, in certain conditions, special care must be taken to ensure the accuracy of the measurements. For instance, it is well known that most solid state detectors perturb dose measurements in water for small megavoltage photon beams (Bouchard et al, 2015a). In such a situation, detector dose responses are often investigated using Monte Carlo simulations, which provide a better understanding of the perturbation effects caused by the detectors (Bouchard et al, 2015b).

Regarding relative proton beam dosimetry, the ICRU Report No. 78 (ICRU 2007) recommends

the use of plane-parallel ionization chambers as reference detectors for depth-dose curve measurements. If the field size is smaller than twice the diameter of the chamber cavity, the IAEA TRS-398 code of practice (IAEA 2000) recommends the use of higher spatial resolution detectors, such as mini-chambers, silicon diodes or diamond detectors. However, TRS-398 stipulates that the suitability of such detectors for depth-dose curve measurements should be verified using a plane- 
promising active volume material for relative dosimetry in narrow or high-pulsed beams, due to its properties such as radiation hardness, atomic number close to water, fast response time, low leakage current, large dynamic range, etc. Moreover, the good performance and reliability of synthetic diamond detectors have increased the interest for this technology (Guerrero et al 2004, Bucciolini et al 2005, Garino et al 2006, Tranchant et al 2008, Almaviva et al 2008, 2009, 2010, Schirru et al 2010, Tromson et al 2010, Betzel et al 2010, Ciancaglioni et al 2012, Venanzio et al 2013, Zani et al 2013, Mandapaka et al 2013, Marsolat et al 2013, 2015).

Two commercial diamond detectors have been distributed for radiotherapy applications: the PTW60003 (no longer marketed) and more recently the PTW60019 microDiamond. For the PTW 60003, a small natural diamond was used as the active volume. The suitability of the PTW 60003 made from natural diamonds of various shapes has been widely investigated for measurement in clinical proton beams (Vatnitsky et al 1995, Onori et al 2000, Pacilio et al 2002, Fidanzio et al 2002). These studies concluded that such devices based on natural diamonds exhibited too significant of a variation of sensitivity with dose rate and proton energy, rendering them inappropriate for accurate dose measurement, even after an empirical correction method was proposed by Fidanzio et al (2002) to improve the depth-dose curves measurement of modulated proton beams.

For the PTW 60019 microDiamond, a synthetic crystal diamond Schottky diode is used (Ciancaglioni et al 2012). This dosimeter has been widely tested and characterized in clinical photon and electron beams (Lechner et al 2013, Laub and Crilly 2014, Morales et al 2014, Ralston et al 2014, Lárraga-Gutiérrez et al 2015, Mancosu et al 2015, Brualla-Gonzalez et al 2015). A precommercial version of this detector developed by the Università di Roma Tor Vergata (Rome, Italy) was tested with clinical proton beams (Mandapaka et al 2013), and its commercial version was evaluated by Akino et al (2015), Gomà et al (2015) and Marsolat et al (2016). These studies have demonstrated that they exhibit a small dose rate and energy dependence and good agreement with plane-parallel ionization chambers. Regarding depth-dose curves, the PTW 60003 detectors were found to significantly underestimate the dose at the Bragg peak position (Bragg peak dose), whereas most of the PTW 60019 microDiamond detectors investigated were found to correctly estimate this dose. This was assumed to be related to the extremely small thickness of their active volume $(1 \mu \mathrm{m})$. In fact, Bichsel (1995) demonstrated that the detector response is highly dependent on the active volume finite dimension. However further investigations about the Bragg peak dose perturbation 
caused by the crystal and the coating are still required. It is also necessary to thoroughly characterize the reproducibility performance of each PTW 60019 microDiamond detector in order to confirm that they exhibit a small energy and dose rate dependence with proton beams. In fact, Marsolat et al (2016) demonstrated a deviation of about 10\% for the Bragg peak dose between four PTW 60019 microDiamond detectors. It should also be noted that an under-response of the PTW 60019 microDiamond in the Bragg peak of a $62 \mathrm{MeV} / \mathrm{n}$ carbon ion beam was recently reported by Rossomme et al (2016).

In the current work, we have developed a synthetic single crystal diamond dosimeter (SCDDPro) which aims to provide accurate and reliable relative dose measurements for proton beams. As opposed to a plane-parallel ionization chamber, a diamond dosimeter allows the performance of measurements in narrow proton beams without radial volume integration. First, the detector design has been optimized in terms of depth response in water for several proton beams using Monte Carlo simulations. Then, an SCDD-Pro prototype was mounted in a water-equivalent holder, and its performance was evaluated in a clinical proton beam line. Finally, the depth-dose curves measured with the SCDD-Pro were compared with a plane-parallel ionization chamber, as recommended by the TRS-398, at a large field size for three different proton beam energies and for a modulated Bragg peak. Unlike the PTW 60019 microDiamond Schottky diode configuration, the SCDD-Pro is based on a high-quality free standing single crystal diamond configuration (i.e. there is neither substrate nor diamond doping, and a bias voltage is required for charge collection) which implies a different approach. From this point of view, the SCDD-Pro is closer to a PTW 60003 than to a PTW 60019 microDiamond. The goal of our work is to provide measurements of depth-dose curves, without Bragg peak dose perturbation, by using this single crystal diamond configuration.

An IBA pencil beam scanning system is being set up at the Proton therapy Center of the Curie Institute (Orsay, France) to complement the current passive scattering system. Thus, we also aim to develope an SCDD-Pro with an active volume that exhibits a smaller radial width than the PTW 60019 microDiamond, in order for the SCDD-Pro device to be more suitable for pencil proton beams. 


\section{MATERIALS AND METHODS}

\subsection{Detector design}

The general design of the SCDD-Pro built at CEA-LIST laboratories (Saclay, France) is schematically described in Figure 1. The SCDD-Pro components are listed below.

- Active volume: The active volume consists of the entire volume of the diamond crystal. An electronic grade synthetic single crystal diamond, from Element Six Ltd., was used. The diamond front surface was $1.0 \mathrm{~mm} \times 1.0 \mathrm{~mm}$ and the active volume thickness $\left(\mathrm{e}_{\mathrm{AV}}\right)$ was chosen in accordance with three aspects: the numerical results presented in this paper, the Bragg peak dose perturbation less than $2 \%$ required by the Proton therapy Center of the Curie Institute and the technical constraint of the electrode design.

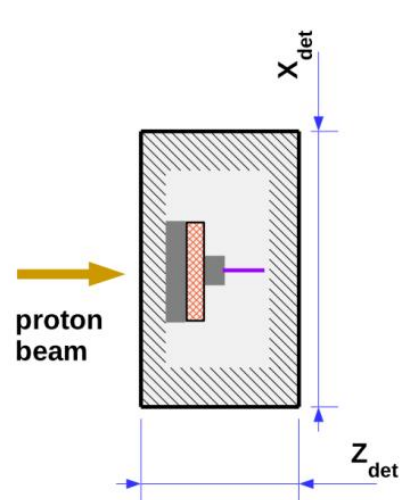

a)

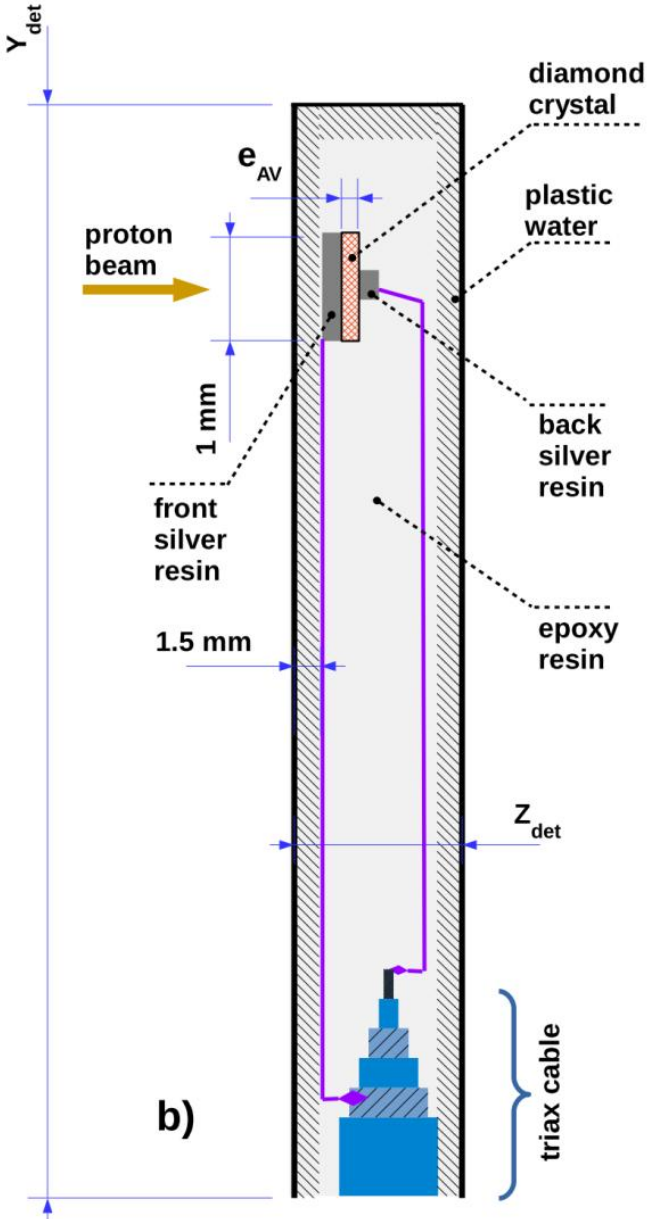

Figure 1: Technical drawing of the diamond dosimeter: (a) top and (b) lateral views. The diamond crystal and the electrical connections are kept inside a Plastic Water housing filled with waterequivalent epoxy resin. 
- Electrodes: The electrodes on the two faces of the diamond crystal were made by depositing a $100 \mathrm{~nm}$ conductive material on the entire front and back surfaces of the crystal in order to reduce the dose rate dependence (Marsolat et al 2015), potentially allowing the use of the SCDD-Pro in high dose rate proton pencil beams.

\subsection{Numerical study of the perturbation} $5 \%$ higher than liquid water. the silver resin is $4.0 \mathrm{~g} / \mathrm{cm}^{3}$.

\subsubsection{Setup of the simulations}

- External coating: The external coating of the detector was manufactured from Plastic Water material. The external coating dimensions were $0.8 \mathrm{~cm}$ in the beam axis direction, and $1.0 \mathrm{~cm} \times 6.0 \mathrm{~cm}$ in the perpendicular plane.

- Internal coating: The internal coating was made of water-equivalent epoxy resin material. According to the manufacturer, the electronic and mass density of this epoxy resin is about

- Triax cable: A tri-axial cable used to connect the device to the electrometers.

- Back silver resin: The aluminum wire and the back silver resin are used to connect the back face of the diamond to the electrical circuit.

- Front silver resin: The front silver resin is used to connect the front face of the diamond to the electrical circuit. The front silver resin has a cylindrical shape with a thickness of about $250 \mu \mathrm{m}$ and a diameter of about $1 \mathrm{~mm}$. According to the manufacturer, the mass density of

Monte Carlo simulations performed with the MCNPX code (version 2.7) (Pelowitz et al 2011) were used to study and reduce the impact of the detector design on the dose curve perturbation in water for proton beams. A water phantom was modeled by a volume of $50 \mathrm{~cm}$ wide and $90 \mathrm{~cm}$ depth filled with water material (mass density $\rho_{\text {water }}$ of $1.00 \mathrm{~g} / \mathrm{cm}^{3}$ ). The phantom was modeled as being surrounded by air material $\left(1.2 \cdot 10^{-3} \mathrm{~g} / \mathrm{cm}^{3}\right)$. Three basic proton beam models were used. For each model, the source was mono-energetic and mono-directional, but the radial distribution and the energy were different. A proton pencil beam of $100 \mathrm{MeV}$ was modeled using a gaussian radial distribution with a full width at half maximum of $5.0 \mathrm{~mm}$, i.e. sigma of about $2 \mathrm{~mm}$. Two proton broad beams of $100 \mathrm{MeV}$ and $220 \mathrm{MeV}$ were modeled using a uniform radial distribution with a radius of $1.5 \mathrm{~cm}$. Concerning the simulation parameters, the transport of the proton, electron, 
positron, neutron and photon particles were enabled. The cut-off energies were $1 \mathrm{keV}$ for photons and electrons and $1 \mathrm{MeV}$ for protons. For the protons, the Vavilov straggling model was used.

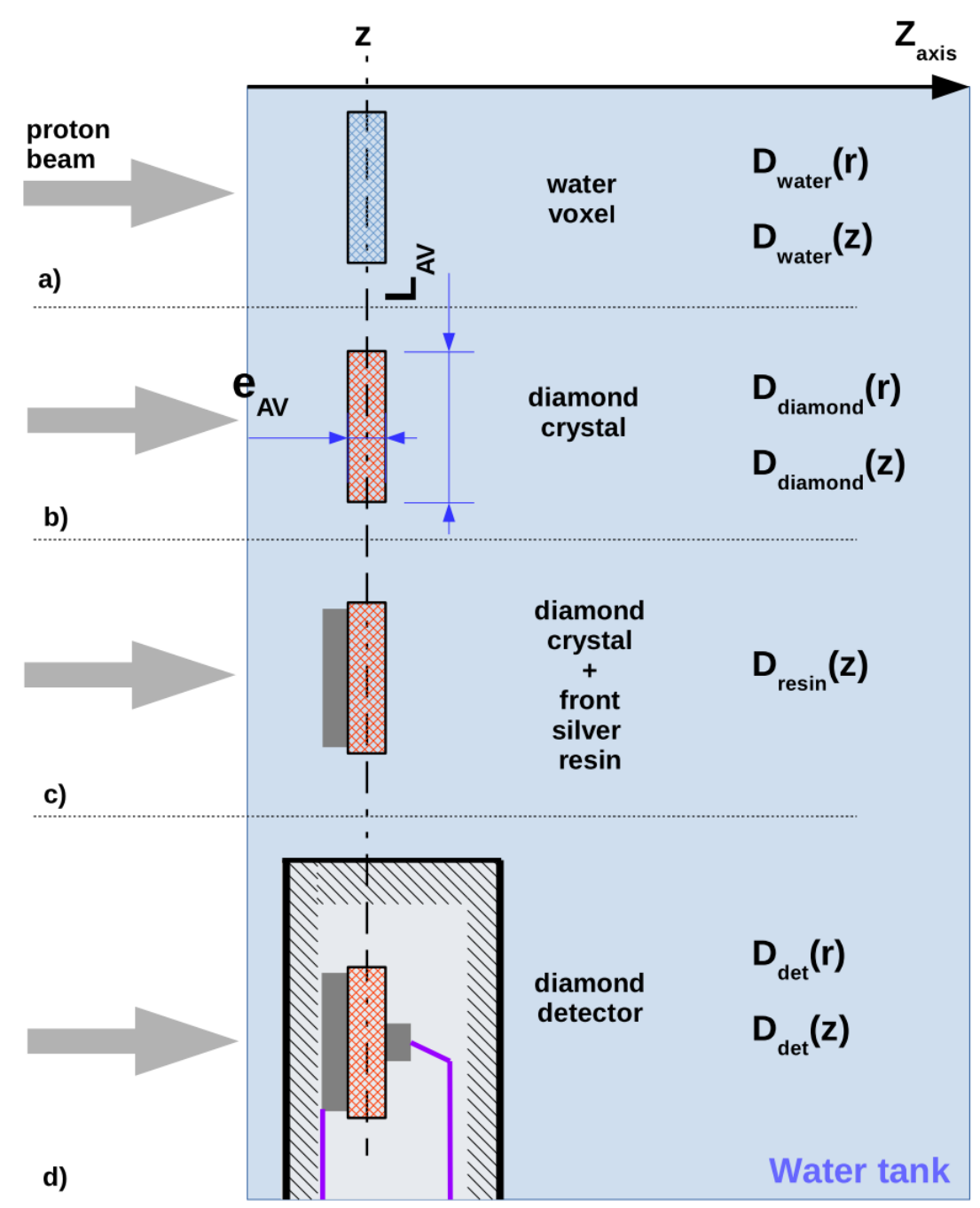

Figure 2: Model used to calculate (a) the profile and the depth-dose curve of reference $\left(D_{\text {water }}(r)\right.$, $\left.D_{\text {water }}(\mathrm{z})\right)$. Models used to calculate the profiles and the depth-dose curves related to the study of the perturbation caused by (b) the diamond crystal alone $\left(\mathrm{D}_{\text {diamond }}(\mathrm{r}), \mathrm{D}_{\text {diamond }}(\mathrm{z})\right)$, (c) the addition of the front silver resin $\left(D_{\text {resin }}(z)\right)$ and $(d)$ the full detector design $\left(D_{\text {det }}(r), D_{\text {det }}(z)\right)$.

For the profile simulations, only the $100 \mathrm{MeV}$ pencil beam and active volumes with an $\mathrm{e}_{\mathrm{AV}}$ of $150 \mu \mathrm{m}$ have been used in order to have a first evaluation of the volume averaging effect caused by the diamond crystal width $\left(\mathrm{L}_{\mathrm{AV}}\right)$ and the full detector design in the penumbra region for beams delivered by pencil beam scanning technique. The active volume center was set at $1.5 \mathrm{~cm}$ in depth and only the radial distance (r) from the beam axis was changed. Simulations were performed to achieve at least a $0.2 \%$ (1-sigma) relative statistical uncertainty in the penumbra region. 
For the depth-dose curve simulations, only active volumes with a $\mathrm{L}_{\mathrm{AV}}$ of $1 \mathrm{~mm}$ have been investigated. The active volume center was set on the beam axis and only the depth position in water was changed with the active volume center set at the point of calculation (z). The dose in the active volume was recorded for different depths along the $\mathrm{Z}$ axis, with the origin being set to the water phantom surface. Simulations were performed to achieve a $0.2 \%, 0.3 \%$ and $0.3 \%$ (1-sigma) relative statistical uncertainties on the Bragg peak dose for the $100 \mathrm{MeV}$ pencil beam, $100 \mathrm{MeV}$ broad beam and $220 \mathrm{MeV}$ broad beam, respectively.

\subsubsection{Perturbation on pencil beam profiles}

The profile without perturbation $\left(\mathrm{D}_{\text {water }}(\mathrm{r})\right)$ was evaluated with a point-like water voxel (Figure 2a) of $0.25 \mathrm{~mm} \times 0.25 \mathrm{~mm} \times 150 \mu \mathrm{m}$. The profiles with the diamond crystal alone $\left(\mathrm{D}_{\text {diamond }}(\mathrm{r})\right)$ were calculated by defining a carbon material with the theoretical mass density of diamond ( $\rho_{\text {diamond }}=3.52 \mathrm{~g} / \mathrm{cm}^{3}$ ) for the active volume. The diamond crystal was modeled with several $\mathrm{L}_{\mathrm{AV}}$ between $0.25 \mathrm{~mm}$ and $4.0 \mathrm{~mm}$ (Figure $2 \mathbf{b})$. Then, the profile with the full detector design $\left(\mathrm{D}_{\operatorname{det}}(\mathrm{r})\right)$, as presented in Figure 1, was calculated with a $\mathrm{L}_{\mathrm{AV}}$ of $1 \mathrm{~mm}$ (Figure 2d). All the profiles were normalized to $100 \%$ at central axis, and the differences $\left(\operatorname{Diff}_{\mathrm{r}}\right)$ compared to the $\mathrm{D}_{\text {water }}(\mathrm{r})$ were calculated. Four features were also derived from $\mathrm{D}_{\text {diamond }}(\mathrm{r})$ : the field size defined as the field at $50 \%$ maximum dose, the $80 \%-20 \%$ lateral penumbra width, and their deviations with those calculated from the $\mathrm{D}_{\text {water }}(\mathrm{r})$. The uncertainties related to the field size and the lateral penumbra width have been estimated at $0.012 \mathrm{~mm}$ (1-sigma).

\subsubsection{Perturbation caused by the diamond crystal on depth-dose curves}

Several $\mathrm{e}_{\mathrm{AV}}$ ranging from $5 \mu \mathrm{m}$ to $500 \mu \mathrm{m}$ were investigated. At the first stage, only the active volume was modeled (Figure 2b) to study the perturbation exclusively caused by the diamond crystal without the detector coating. The active volume was defined with the $\rho_{\text {diamond }}$ carbon material and the depth-dose curves with the diamond crystal alone $\left(D_{\text {diamond }}(z)\right)$ were calculated with the three proton beams. Then, the depth-dose curves without perturbation $\left(\mathrm{D}_{\text {water }}(\mathrm{z})\right)$ were calculated to be used as reference. This reference was estimated by recording the dose in a water voxel (Figure 2a) of exactly the same size as the diamond crystal in order to avoid a possible volume averaging effect in the analysis. 
The raw values of $D_{\text {water }}(\mathrm{z})$ were divided by the maximum value $\left(\mathrm{D}_{\text {water,max }}\right)$ at the Bragg peak position and expressed in percents $(\%)$ of $\mathrm{D}_{\text {water,max }}$. Then the raw values of $\mathrm{D}_{\text {diamond }}(\mathrm{z})$ were normalized to the $\mathrm{D}_{\text {water }}(\mathrm{z})$ mean value at the water phantom entrance by considering the values between 0 and $1.5 \mathrm{~cm}$ in depth. As the perturbation in active volume at the beginning of the depthdose curve is less important than at the end, the $\mathrm{D}_{\text {diamond }}(\mathrm{z})$ normalization was done at the water phantom entrance to ease the discussion on the Bragg peak shape.

More specifically, the effect of the diamond mass density on depth-dose curves was investigated for the $\mathrm{e}_{\mathrm{AV}}$ of $500 \mu \mathrm{m}$ with the $100 \mathrm{MeV}$ pencil beam in order to provide an explanation of the mechanism by which the active volume density affects the dose in the active volume itself. For this purpose, the active volume was set with the water atomic composition $\left(\mathrm{H}_{2} \mathrm{O}\right)$, but the mass density

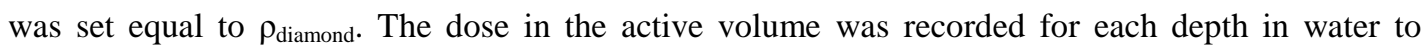
calculate the depth-dose curve, denoted $D_{\text {water }}\left[\rho_{\text {diamond }}\right](z)$. Similarly to $D_{\text {diamond }}(z)$, the raw values of $D_{\text {water }}\left[\rho_{\text {diamond }}\right](z)$ were normalized to $D_{\text {water }}(z)$ entrance. The perturbation caused by the active volume mass density will be discussed by comparing $\mathrm{D}_{\text {water }}\left[\rho_{\text {diamond }}\right](\mathrm{z})$ and $\mathrm{D}_{\text {water }}(\mathrm{z})$ calculated for the $\mathrm{e}_{\mathrm{AV}}$ of $500 \mu \mathrm{m}$. To achieve this, the difference as a function of depth, denoted by $\Delta_{\text {density }}$ (Equation 1), was calculated to point out specific depths $\left(\mathrm{Z}_{\mathrm{i}}\right)$ relative to the mass density effect.

$$
\Delta_{\text {density }}=\mathrm{D}_{\text {water }}\left[\rho_{\text {diamond }}\right](\mathrm{z})-\mathrm{D}_{\text {water }}(z) \quad \text { Equation } 1
$$

For these depths, the mean energy in the active volume $\left(\mathrm{E}_{\mathrm{AV}}\right)$ was calculated by Monte Carlo simulation. Then, the corresponding proton ranges (in the continuous slowing down approximation), $\operatorname{Range}_{w a t e r}\left[\rho_{w a t e r}\right]$ and Range ${ }_{w a t e r}\left[\rho_{\text {diamond }}\right]$, in water material with a normal mass density and a diamond mass density, respectively, were taken from the PSTAR program tables and compared to the diamond crystal thickness.

\subsubsection{Perturbation caused by the design features on depth-dose curves}

At the second stage, the front silver resin was added in the modeling (Figure 2c) to study the impact of this element on the depth-dose curves. The front silver resin was modeled by a thin cylinder of $1 \mathrm{~mm}$ in diameter and $250 \mu \mathrm{m}$ in thickness. The mass density and atomic composition of the silver resin material was defined according to the data provided by the manufacturer. The depthdose curves related to this modeling $\left(\mathrm{D}_{\text {resin }}(\mathrm{z})\right)$ were calculated and, similarly to $\mathrm{D}_{\text {diamond }}(\mathrm{z})$, the raw values of $D_{\text {resin }}(z)$ were normalized to $D_{\text {water }}(z)$ entrance. 
The effect of the front silver resin on depth-dose curves was investigated in more details for the $\mathrm{e}_{\mathrm{AV}}$ of $150 \mu \mathrm{m}$ with the $100 \mathrm{MeV}$ pencil beam in order to provide an explanation of the mechanism by which the front silver resin affect the dose deposited in the active volume. To this end, the proton

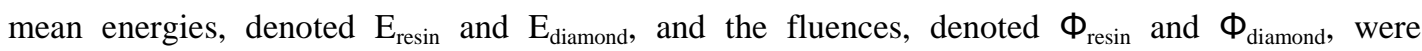
calculated at each depth in water with and without the front silver resin respectively. The mean energy is used instead of the energy spectrum in order to simplify the demonstration. $D_{\text {resin }}(z)$ can be express as Equation 2, where $\Delta \mathrm{E}$ and $\Delta \Phi$ are the energy and fluence variations due to the addition of the front silver resin, and $\mathrm{S} / \rho_{\text {diamond }}$ is the mass stopping power for protons.

$$
\mathrm{D}_{\text {resin }}(\mathrm{z}) \propto \phi_{\text {resin }} \cdot \frac{\mathrm{S}\left(\mathrm{E}_{\text {resin }}\right)}{\rho_{\text {diamond }}}=\left(\phi_{\text {diamond }}+\Delta \phi\right) \cdot \frac{\mathrm{S}\left(\mathrm{E}_{\text {diamond }}+\Delta \mathrm{E}\right)}{\rho_{\text {diamond }}} \quad \text { Equation } 2
$$

with $\Delta \phi \leq 0$ and $\Delta \mathrm{E} \leq 0$ for a high density material in front of the active volume

The first-order Taylor expansion of Equation 2 leads to Equation 3.

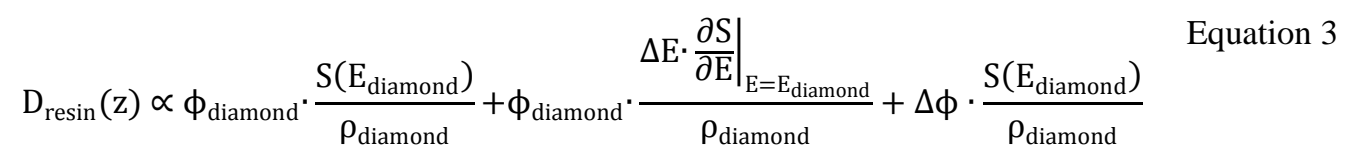

And $D_{\text {resin }}(z)$ can be expressed as Equation 4, where $\varepsilon_{\Delta \mathrm{E}}$ (Equation 5) and $\varepsilon_{\Delta \Phi}$ (Equation 6) are the perturbation factors due to $\Delta \mathrm{E}$ and $\Delta \Phi$ respectively. For each depth in water, these two perturbation factors were calculated.

$$
\begin{aligned}
& \mathrm{D}_{\text {resin }}(\mathrm{z})=\mathrm{D}_{\text {diamond }}(\mathrm{z}) \times\left(1+\varepsilon_{\Delta \mathrm{E}}+\varepsilon_{\Delta \phi}\right) \text { with } \varepsilon_{\Delta \mathrm{E}} \geq 0 \text { and } \varepsilon_{\Delta \phi} \leq 0 \quad \text { Equation } 4 \\
& \begin{array}{ll}
\varepsilon_{\Delta \mathrm{E}}=\left.\frac{\Delta E}{\mathrm{~S}\left(\mathrm{E}_{\text {diamond }}\right)} \cdot \frac{\partial \mathrm{S}}{\partial \mathrm{E}}\right|_{\mathrm{E}=\mathrm{E}_{\text {diamond }}} & \text { Equation 5 }
\end{array} \\
& \begin{array}{ll}
\varepsilon_{\Delta \phi}=\Delta \phi & \text { Equation } 6
\end{array}
\end{aligned}
$$

Finally, the remaining parts of the detector were added to the model (Figure 2d) to numerically estimate the perturbation caused by the full detector design on depth-dose curves. Only the $\mathrm{e}_{\mathrm{AV}}$ of $150 \mu \mathrm{m}$ was investigated since it was the real diamond crystal thickness mounted in the SCDD-Pro prototype built in this work. The depth-dose curves related to the whole detector modeling $\left(\mathrm{D}_{\operatorname{det}}(\mathrm{z})\right)$ were calculated and the raw values of $D_{\text {det }}(z)$ were normalized to $D_{\text {water }}(z)$ entrance. 


\subsubsection{Evaluation of the Bragg peak dose errors}

The maximum dose value $\left(D_{\max }\right)$ at Bragg peak position was determined for $D_{\text {diamond }}(z), D_{\text {resin }}(z)$ and $D_{\text {det }}(z)$. Then, the deviation of $D_{\text {max }}$ from the reference value $D_{\text {water,max }}$ was calculated by Equation 7 and denoted $\Delta \mathrm{Peak}_{\mathrm{MC}}$

$$
\Delta \text { Peak }_{\mathrm{MC}}(\%)=\mathrm{D}_{\max }(\%)-\mathrm{D}_{\text {water,max }}(\%)=\mathrm{D}_{\max }(\%)-100 \% \quad \text { Equation } 7
$$

The range shifts $\left(\Delta\right.$ Range $\left._{M C}\right)$, due to the diamond crystal, the front silver resin and the full detector design, were also calculated by Equation 8.

$$
\Delta \text { Range }_{\mathrm{MC}}=\text { Range }_{90 \%}-\text { Range }_{\text {water }, 90 \%} \quad \text { Equation } 8
$$

Range $_{90 \%}$ is the depth distal to the Bragg peak, where the dose is $90 \%$ for $\mathrm{D}_{\text {diamond }}(\mathrm{z}), \mathrm{D}_{\text {resin }}(\mathrm{z})$ or $\mathrm{D}_{\text {det }}(\mathrm{z})$. Range $\mathrm{water}, 90 \%_{\text {is }}$ the depth distal to Bragg peak, where the dose is $90 \%$ for $\mathrm{D}_{\text {water }}(\mathrm{z})$. The $\Delta$ Peak $_{\mathrm{MC}}$ and $\Delta$ Range $_{\mathrm{MC}}$, representing the deviations of the Bragg peak dose and position from the reference, were calculated for all $\mathrm{e}_{\mathrm{AV}}$ investigated and for the three simulated proton beams.

\subsection{Experimental study}

\subsubsection{Characterization of the diamond detector}

The electrical characterization of the SCDD-Pro was evaluated under a $\mathrm{kV}$ radiation beam produced by an X-Ray generator (Oxford-instrument, XTF5011/75). The SCDD-Pro was placed in the beam with a dose rate of $6 \mathrm{~Gy} / \mathrm{min}$ at measurement point, and connected to a Keithley 6517A electrometer. The current-voltage response of the SCDD-Pro was measured in the range of $-100 \mathrm{~V}$ to $+100 \mathrm{~V}$ to estimate the best voltage for maximum charge collection efficiency. Then, the current as a function of time was measured for a bias voltage of $+50 \mathrm{~V}$, at a sampling rate of $5 \mathrm{~s}^{-1}$, in order to evaluate the SCDD-Pro stability. The SCDD-Pro signal-to-noise ratio was calculated as the ratio of the mean value to the standard deviation value of the current.

\subsubsection{Experimental setup}

Measurements in clinical proton beams were performed in one of the horizontal beam line at the Proton therapy Center of the Curie Institute. This beam line is dedicated to the treatment of head and neck tumors and has been described elsewhere (Stankovskiy et al 2009). Three binary filters were used in this work: $48 \mathrm{~mm}$ of Lexan $+2.5 \mathrm{~mm}$ of lead, $95.75 \mathrm{~mm}$ of Lexan $+1.0 \mathrm{~mm}$ of lead, and 
$160 \mathrm{~mm}$ of Lexan $+1.0 \mathrm{~mm}$ of lead to produce proton beam energies of about $163 \mathrm{MeV}, 138 \mathrm{MeV}$ and $89 \mathrm{MeV}$ respectively. A modulated Bragg peak of the $138 \mathrm{MeV}$ beam, further referred to as the m138 MeV proton beam, was also produced using a $6 \mathrm{~cm}$ range modulator wheel with a binary filter of $95.75 \mathrm{~mm}$ of Lexan and $1.0 \mathrm{~mm}$ of lead in order to create a Spread-Out Bragg Peak.

Two active detectors were used in this study: the SCDD-Pro developed in this work and a commercial PPC05 plane-parallel ionization chamber from IBA. All measurements in clinical proton beams were performed in an IBA BluePhantom ${ }^{2}$ water tank. The water tank has a fixation system motorized by stepper motors in the three dimensions allowing a detector positioning accuracy of $0.1 \mathrm{~mm}$. The distance from the last collimator to the water tank entrance window was set to $5.0 \mathrm{~cm}$ and the field diameter was $12 \mathrm{~cm}$. The dose rate was always set to $2.2 \mathrm{~Gy} / \mathrm{min}$ except for the study of the SCDD-Pro dose rate dependence.

The IBA PPC05 was used to obtain the experimental reference data of the depth-dose curves as recommended by international dosimetric protocols (IAEA 2000, ICRU 2007). This plane-parallel ionization chamber has a cylindrical active volume of $9.9 \mathrm{~mm}$ in diameter and $0.6 \mathrm{~mm}$ in thickness, allowing a good spatial resolution for depth-dose curve measurements in broad beams.

Each detector was attached to the motorized system using a plastic holder (Figure 3). The SCDD-Pro orientation was the same as in the Monte Carlo study (Figure 1). IBA PPC05 and SCDD-Pro were used with a bias voltage of $+300 \mathrm{~V}$ and $+50 \mathrm{~V}$ respectively. The detectors' depths in water were adjusted considering the effective point of measurement and the water-equivalent thickness of the water tank entrance window. The detectors' active volumes were accurately centered on the beam axis after measuring two profiles in perpendicular directions (in-line and cross-line directions).

\subsubsection{Dosimetrical characterization of the diamond detector}

The SCDD-Pro dosimetrical characterization at the Proton therapy Center of the Curie Institute was performed with the dosimeter connected to a PTW Unidos Webline electrometer. The SCDD-Pro was positioned on the central axis of the m138 MeV proton beam, at a depth in water of $10 \mathrm{~cm}$ in order to be placed in the middle of the Spread-Out Bragg Peak, which is referred as the reference condition. In these conditions, the delivered dose was 1.0 Gy for $100 \mathrm{MU}$. 

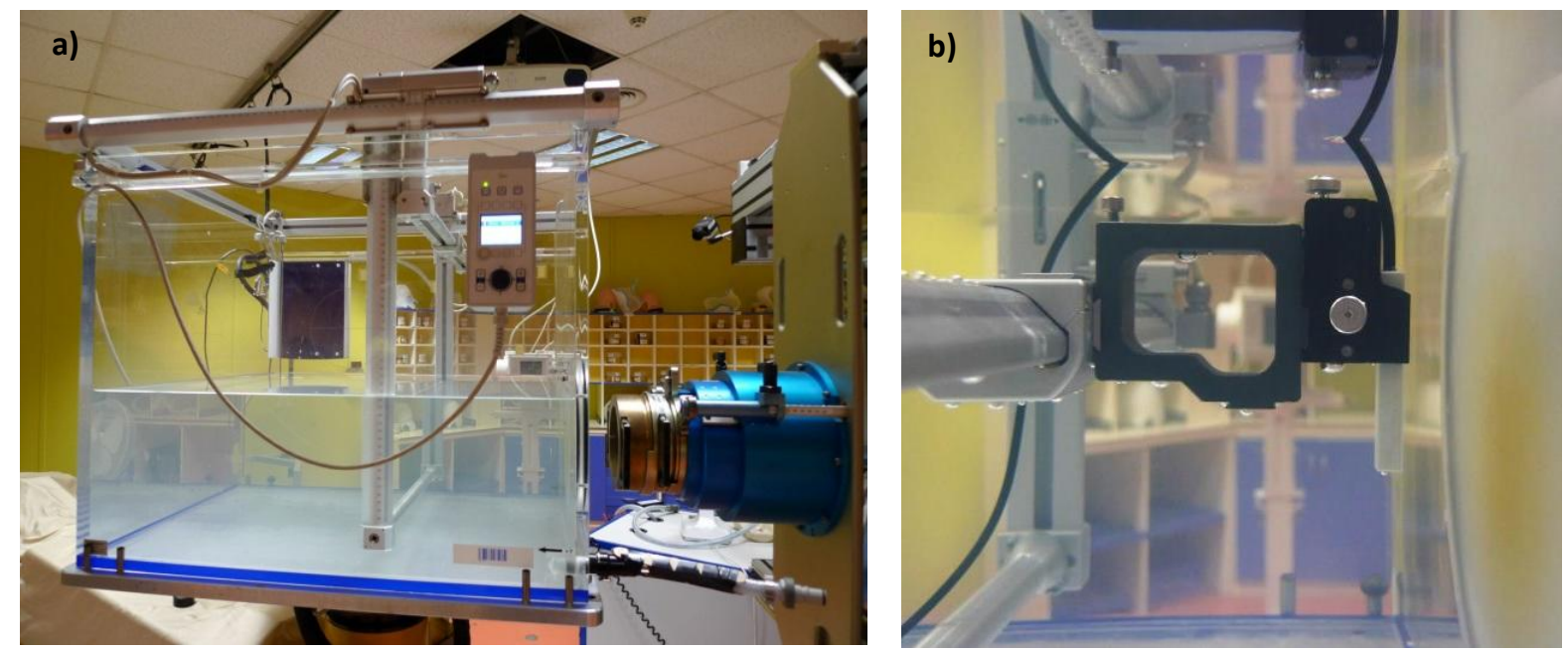

Figure 3: Pictures of (a) the water tank at the end of the proton beam line and (b) the SCDD-Pro attached to the motorized system in water.

After a pre-irradiation of $5 \mathrm{~Gy}$, the repeatability of SCDD-Pro was evaluated by measuring 18 charges $\left(\mathrm{q}_{\mathrm{i}}\right)$ for consecutive irradiations with a constant delivered dose of $1.0 \mathrm{~Gy}$. The mean charge $(\mathrm{Q})$ and the standard deviation $\sigma(\mathrm{Q})$ of the $\mathrm{q}_{\mathrm{i}}$ values were calculated, and the SCDD-Pro sensitivity in proton beams was estimated as the ratio of $\mathrm{Q}$ to the delivered dose, expressed in $\mathrm{nC} / \mathrm{Gy}$. The integrated background charge $\left(\mathrm{Q}_{\mathrm{bck}}\right)$ was measured when the proton beam was turned-off during the same time as the previous delivered dose of $1.0 \mathrm{~Gy}$. The SCDD-Pro signal-to-background ratio was calculated as the ratio of $\mathrm{Q}$ to $\mathrm{Q}_{\mathrm{bck}}$.

The dose rate dependence of SCDD-Pro was studied by varying the beam intensity from $1.0 \mathrm{~Gy} / \mathrm{min}$ to $5.5 \mathrm{~Gy} / \mathrm{min}$. For each measurement, a dose of $1.0 \mathrm{~Gy}$ was delivered and four measurements were performed for each dose rate. The deviation from the maximum dose rate was calculated as $\left(Q_{\dot{D}} / Q_{\dot{D}_{0}}\right)-1$, where $Q_{\dot{D}}$ is the charge for the studied dose rate $(\dot{D})$ and $Q_{\dot{D}_{0}}$ is the charge for the maximum dose rate $\left(\dot{\mathrm{D}}_{0}\right)$, i.e. $5.5 \mathrm{~Gy} / \mathrm{min}$.

The dose linearity of SCDD-Pro was studied for the range between $0.05 \mathrm{~Gy}$ and $5 \mathrm{~Gy}$. For each dose (D), 10 charge measurements were performed for doses below $0.2 \mathrm{~Gy}$ and at least four for doses above $0.2 \mathrm{~Gy}$. The deviation from linearity (Dev.lin.) was calculated as the relative deviation of the sensitivity from the one at the maximum delivery dose $\left(D_{0}\right)$ by Equation 9 , where $Q_{D}$ was the mean charge related to the dose $\mathrm{D}$ and $\mathrm{Q}_{\mathrm{D}_{0}}$ was the mean charge related to the maximum dose $\mathrm{D}_{0}$.

$$
\text { Dev.lin. }(\%)=\left(\frac{\mathrm{Q}_{\mathrm{D}} / \mathrm{D}}{\mathrm{Q}_{\mathrm{D}_{0}} / \mathrm{D}_{0}}-1\right) \times 100
$$

Equation 9 


\subsubsection{Evaluation of the detector response for depth-dose curves measurement}

For depth-dose curves measurement $\left(\mathrm{D}_{\mathrm{SCDD}-\mathrm{Pro}}(\mathrm{z}), \mathrm{D}_{\mathrm{PPC} 05}(\mathrm{z})\right)$, the SCDD-Pro and an IBA PPC05 plane-parallel chamber were connected to the electrometer integrated into the water tank. The scan

was controlled by the software OmniPro Accept $7 . \mathrm{D}_{\mathrm{SCDD}-\mathrm{Pro}}(\mathrm{z})$ and $\mathrm{D}_{\mathrm{PPC} 05}(\mathrm{z})$ of the $163 \mathrm{MeV}, 138 \mathrm{MeV}, 89 \mathrm{MeV}$ and m138 MeV proton beams were measured. For each beam, the $\mathrm{D}_{\mathrm{PPC} 05}(\mathrm{z})$ values were normalized to the maximum dose, and the $\mathrm{D}_{\text {SCDD-Pro }}(\mathrm{z})$ values were normalized to the dose near the water surface, i.e. the mean dose value calculated with $\mathrm{D}_{\mathrm{PPC} 05}(\mathrm{z})$ using the measurements between $2.5 \mathrm{~cm}$ and $4.0 \mathrm{~cm}$. No response correction was applied to the experimental SCDD-Pro data for either the water-to-dosimeter material stopping power ratio or for dose rate dependence. Then, the difference, $\operatorname{Diff}_{\mathrm{z}}$, of the $\mathrm{D}_{\mathrm{SCDD}-\mathrm{Pro}}(\mathrm{z})$ from the $\mathrm{D}_{\mathrm{PPC} 05}(\mathrm{z})$ was calculated by Equation 10.

$$
\operatorname{Diff}_{\mathrm{z}}=\mathrm{D}_{\mathrm{SCDD}-\mathrm{Pro}}(\mathrm{z})-\mathrm{D}_{\mathrm{PPC} 05}(\mathrm{z}) \quad \text { Equation } 10
$$

Three features were derived from the curves with the unmodulated proton beams: the difference, $\Delta$ Peak $_{\text {exp }}$, of the $\mathrm{D}_{\mathrm{SCDD}-\mathrm{Pro}}(\mathrm{z})$ maximum dose $\left(\mathrm{D}_{\mathrm{SCDD}-\mathrm{Pro}, \mathrm{max}}\right)$ at Bragg peak position (Equation 11), the

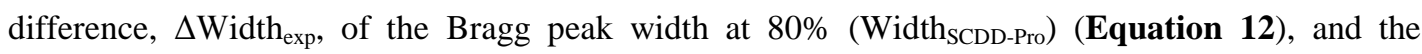
difference, $\Delta \mathrm{DDF}_{\mathrm{exp}}$, of the $\mathrm{D}_{\mathrm{SCDD}-\mathrm{Pro}}(\mathrm{z})$ distal-dose fall-off distance $\left(\mathrm{DDF}_{\mathrm{SCDD}-\mathrm{Pro}}\right)$ (Equation 13) were calculated with respect to the IBA PPC05 measurements $\left(\mathrm{D}_{\mathrm{PPC} 05, \mathrm{max}}\right.$, Width ${ }_{\mathrm{PPC} 05}$ and $\left.\mathrm{DDF}_{\mathrm{PPC} 05}\right)$. The distal-dose fall-off distance is defined as the distance between the $80 \%$ and $20 \%$ distal points.

$$
\begin{array}{cc}
\Delta \text { Peak }_{\text {exp }}=\mathrm{D}_{\text {SCDD-Pro,max }}-\mathrm{D}_{\mathrm{PPC} 05, \max } & \text { Equation } 11 \\
\Delta \mathrm{Width}_{\mathrm{exp}}=\text { Width }_{\mathrm{SCDD}-\mathrm{Pro}}-\text { Width }_{\mathrm{PPC} 05} & \text { Equation } 12 \\
\Delta \mathrm{DDF}_{\mathrm{exp}}=\mathrm{DDF}_{\mathrm{SCDD}-\mathrm{Pro}}-\mathrm{DDF}_{\mathrm{PPC} 05} & \text { Equation } 13
\end{array}
$$




\section{RESULTS AND DISCUSSION}

\subsection{Monte Carlo study of the perturbations caused by the detector}

\subsubsection{Pencil beam profiles}

$\mathrm{D}_{\text {water }}(\mathrm{r}), \mathrm{D}_{\text {diamond }}(\mathrm{r})$ and $\mathrm{D}_{\text {det }}(\mathrm{r})$ calculated by Monte Carlo simulations are shown on Figure 4 $\operatorname{Diff}_{\mathrm{r}}$ is smaller than $1 \%$ for the diamond crystal alone with $\mathrm{L}_{\mathrm{AV}}$ smaller than or equal to $1.0 \mathrm{~mm}$ and for the full detector design. Diff $\mathrm{r}_{\mathrm{r}}$ becomes larger than $2 \%$ for a diamond crystal with $\mathrm{L}_{\mathrm{AV}}$ of $2 \mathrm{~mm}$ and this difference increases when the $\mathrm{L}_{\mathrm{AV}}$ increases. No differences are observed between $\mathrm{D}_{\text {diamond }}(\mathrm{r})$ with $\mathrm{L}_{\mathrm{AV}}$ of $1 \mathrm{~mm}$ and $\mathrm{D}_{\text {det }}(\mathrm{r})$, which means that the effect of the design features (i.e. other than the active volume) on the profile is not significant. The field sizes and lateral penumbra widths related to $\mathrm{D}_{\text {diamond }}(\mathrm{r})$ are given in Table $\mathbf{1}$, as well as the deviation from $\mathrm{D}_{\text {water }}(\mathrm{r})$. For $\mathrm{L}_{\mathrm{AV}}$ smaller than or equal to $1.0 \mathrm{~mm}$, the deviations are within the uncertainties. Thus no perturbation is found with a diamond crystal width up to $1 \mathrm{~mm}$. For $\mathrm{L}_{\mathrm{AV}}$ larger or equal to $2.0 \mathrm{~mm}$, the field size and lateral penumbra width deviations are larger than $0.17 \mathrm{~mm}$ and $0.08 \mathrm{~mm}$, respectively. This perturbation is caused by a volume averaging effect produced by the large active surface of the diamond crystal compared to the lateral beam size. These results demonstrate that a diamond crystal with a $\mathrm{L}_{\mathrm{AV}}$ of $1 \mathrm{~mm}$ or less can evaluate a profile without volume averaging effect for a proton pencil beam of $5 \mathrm{~mm}$ in full width at half maximum. The correct estimation of profiles for broader proton pencil beams is also expected with this detector design.

Table 1: Values of field size and lateral penumbra width at water phantom entrance for a $100 \mathrm{MeV}$ pencil beam and deviations from the point-like water voxel modeling.

\begin{tabular}{lccccc}
\hline \hline & \multicolumn{2}{c}{ Field sizes } & & \multicolumn{2}{c}{ Lateral penumbra widths } \\
\cline { 2 - 3 } \cline { 5 - 6 } $\mathrm{L}_{\mathrm{AV}}(\mathrm{mm})$ & $\begin{array}{c}\text { Value } \\
(\mathrm{mm})\end{array}$ & $\begin{array}{c}\text { Deviation } \\
(\mathrm{mm})\end{array}$ & & $\begin{array}{c}\text { Value } \\
(\mathrm{mm})\end{array}$ & $\begin{array}{c}\text { Deviation } \\
(\mathrm{mm})\end{array}$ \\
\hline 0.25 & 5.05 & +0.00 & & 2.43 & +0.00 \\
0.5 & 5.05 & +0.00 & & 2.42 & -0.01 \\
1.0 & 5.07 & +0.02 & & 2.44 & +0.01 \\
2.0 & 5.22 & +0.17 & & 2.51 & +0.08 \\
3.0 & 5.46 & +0.41 & & 2.61 & +0.18 \\
4.0 & 5.81 & +0.76 & & 2.75 & +0.32 \\
\hline \hline
\end{tabular}




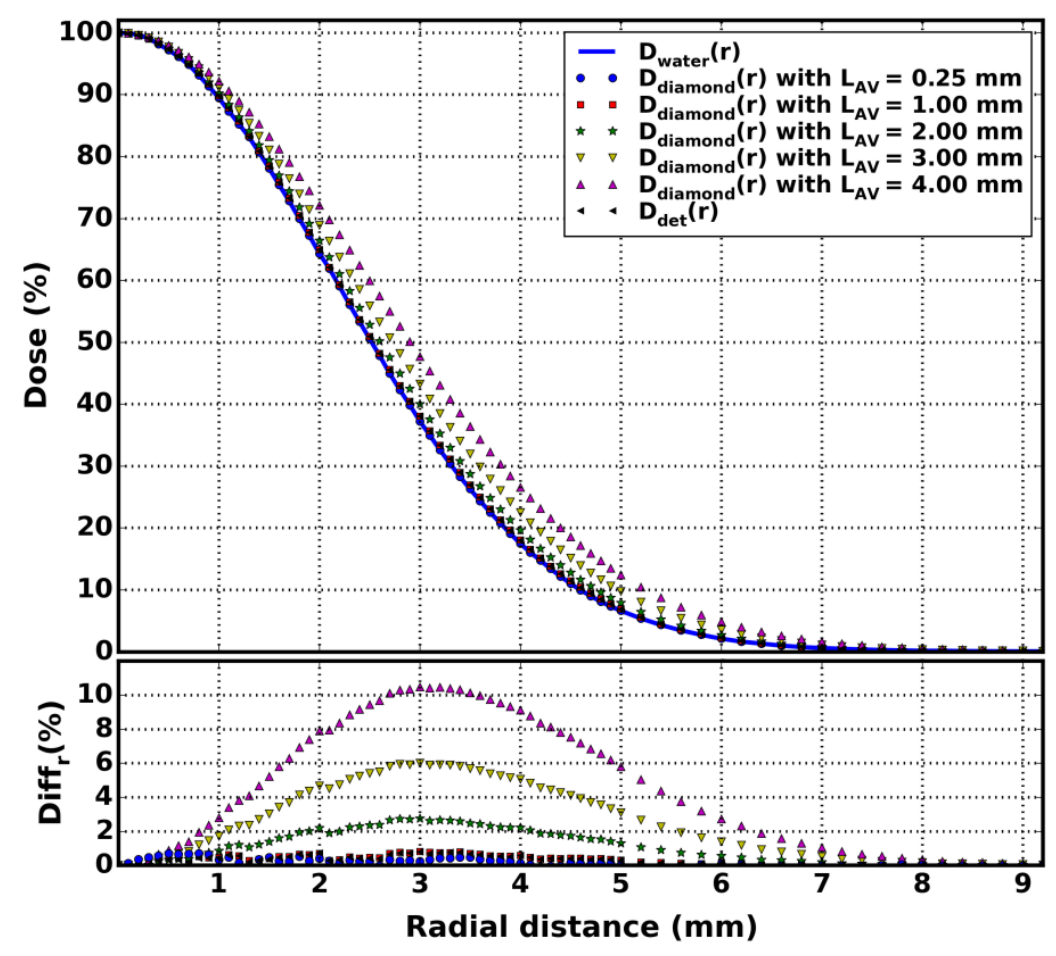

Figure 4: Profiles calculated by Monte Carlo simulations at $1.5 \mathrm{~cm}$ in depth for a $100 \mathrm{MeV}$ proton pencil beam. The profiles for the point-like water voxel $\left(D_{\text {water }}(r)\right)$, the several diamond crystal widths $\left(D_{\text {diamond }}(r)\right)$ and the full detector design $\left(D_{\text {det }}(r)\right)$ are plotted on the top graph. Differences from $D_{\text {water }}(r)$ are plotted on the bottom graph.

\subsubsection{Influence of the diamond crystal thickness on depth-dose curves}

The $D_{\text {water }}(z)$ and $D_{\text {diamond }}(z)$ for three $e_{A V}$ values $(5,150$ and $500 \mu \mathrm{m})$ are reported in Figure 5. The $\mathrm{D}_{\text {det }}(\mathrm{z})$ is also reported for an $\mathrm{e}_{\mathrm{AV}}$ of $150 \mu \mathrm{m}$. For clarity, only the results around the Bragg peak are shown. All depth-dose curves are equal at water phantom entrance, and all $\Delta \mathrm{Peak}_{\mathrm{MC}}(\%)$ and $\Delta$ Range $_{\mathrm{MC}}(\mathrm{mm})$ values are reported in Table 2. From Table 2 and Figure 5, it can be noted that the depth-dose curve perturbation does not depend on the beam size for the $100 \mathrm{MeV}$ proton beams.

For an $\mathrm{e}_{\mathrm{AV}}$ of $5 \mu \mathrm{m}$, the Bragg peak is at the same position for both the diamond and water active volumes. For beam energies of $100 \mathrm{MeV}$ and $220 \mathrm{MeV}$, the Bragg peak position is at $7.58 \mathrm{~cm}$ and $30.15 \mathrm{~cm}$, and $\Delta$ Range $_{\mathrm{MC}}$ is less than $0.1 \mathrm{~mm}$ and $0.3 \mathrm{~mm}$, respectively. $\mathrm{D}_{\max }$ is systematically lower than $\mathrm{D}_{\text {water,max }}$, and $\Delta$ Peak $_{\mathrm{MC}}$ is between $-2.2 \%$ and $-2.7 \%$. Although an $\mathrm{e}_{\mathrm{AV}}$ of $5 \mu \mathrm{m}$ does not change the Bragg peak position, the simulations display an under-estimation of the Bragg peak dose for all investigated beams. Despite the extremely small thickness, the diamond crystal perturbs the Bragg peak dose. 
For an $\mathrm{e}_{\mathrm{AV}}$ of $150 \mu \mathrm{m}$, the Bragg peak position from a diamond active volume is shifted by about $0.2 \mathrm{~mm}$ and $0.4 \mathrm{~mm}$ toward the entrance for beam energies of $100 \mathrm{MeV}$ and $220 \mathrm{MeV}$, respectively, compared to a water active volume. Similarly to the $\mathrm{e}_{\mathrm{AV}}$ of $5 \mu \mathrm{m}, \mathrm{D}_{\max }$ is systematically lower than $\mathrm{D}_{\text {water,max }} . \Delta$ Peak $_{\mathrm{MC}}$ is $-0.7 \%,-1.1 \%$ and $-2.2 \%$ for the $100 \mathrm{MeV}$ pencil beam, $100 \mathrm{MeV}$ and $220 \mathrm{MeV}$ broad beams, respectively. Thus, the perturbation is less important with only a small shift on the Bragg peak position.

For an $\mathrm{e}_{\mathrm{AV}}$ of $500 \mu \mathrm{m}$, the Bragg peak position from the diamond active volume is shifted by about $0.7 \mathrm{~mm}$ and $0.6 \mathrm{~mm}$ toward the entrance for beam energies of $100 \mathrm{MeV}$ and $220 \mathrm{MeV}$, respectively, compared to the water active volume. A large under-estimation of the Bragg peak dose is found at a beam energy of $100 \mathrm{MeV}: \Delta$ Peak $_{\mathrm{MC}}$ are $-4.3 \%$ and $-4.9 \%$ for the $100 \mathrm{MeV}$ pencil and broad beams, respectively. However, good agreement on the Bragg peak dose is found at a beam energy of $220 \mathrm{MeV}$ : $\Delta$ Peak $_{\mathrm{MC}}$ is $-0.6 \%$ for the $220 \mathrm{MeV}$ broad beam.

Table 2: Values of $\Delta$ Peak $_{M C}$, the deviation of the Bragg peak dose, and $\Delta$ Range $_{M C}$, the Bragg peak position shift calculated by Monte Carlo simulations.

\begin{tabular}{|c|c|c|c|c|c|c|c|}
\hline & \multirow[b]{2}{*}{$e_{A V}(\mu m)$} & \multicolumn{3}{|c|}{ Single crystal diamond alone } & \multicolumn{3}{|c|}{ Single crystal diamond with front silver resin } \\
\hline & & $\begin{array}{c}100 \mathrm{MeV} \\
\text { pencil beam }\end{array}$ & $\begin{array}{c}100 \mathrm{MeV} \\
\text { broad beam }\end{array}$ & $\begin{array}{c}220 \mathrm{MeV} \\
\text { broad beam }\end{array}$ & $\begin{array}{c}100 \mathrm{MeV} \\
\text { pencil beam }\end{array}$ & $\begin{array}{c}100 \mathrm{MeV} \\
\text { broad beam }\end{array}$ & $\begin{array}{c}220 \mathrm{MeV} \\
\text { broad beam }\end{array}$ \\
\hline \multirow{9}{*}{$\begin{array}{c}\Delta \text { Peak }_{M C} \\
(\%)\end{array}$} & 5 & -2.3 & -2.2 & -2.7 & 1.2 & 0.3 & -1.7 \\
\hline & 50 & -3.0 & -3.0 & -2.6 & -0.5 & -0.9 & -0.8 \\
\hline & 100 & -0.4 & -0.6 & -2.3 & 1.8 & 1.1 & -1.0 \\
\hline & 150 & -0.7 & -1.1 & -2.2 & 1.1 & 0.3 & -1.3 \\
\hline & 200 & -1.9 & -2.4 & -2.4 & -0.5 & -1.3 & -2.4 \\
\hline & 250 & -2.5 & -3.0 & -1.4 & -1.3 & -2.1 & -1.4 \\
\hline & 300 & -2.7 & -3.3 & -0.3 & -1.7 & -2.4 & -0.5 \\
\hline & 400 & -3.0 & -3.5 & -0.1 & -2.3 & -2.8 & -0.5 \\
\hline & L 500 & -4.3 & -4.9 & -0.6 & -3.9 & -4.7 & -1.0 \\
\hline \multirow{9}{*}{$\begin{array}{c}\Delta \text { Range }_{M C} \\
\quad(\mathrm{~mm})\end{array}$} & 5 & $<0.10$ & $<0.10$ & $<0.30$ & -0.14 & -0.16 & $<0.30$ \\
\hline & 50 & -0.16 & -0.17 & -0.34 & -0.24 & -0.25 & $<0.30$ \\
\hline & 100 & -0.13 & -0.13 & -0.36 & -0.24 & -0.25 & -0.33 \\
\hline & 150 & -0.19 & -0.20 & -0.40 & -0.32 & -0.28 & -0.41 \\
\hline & 200 & -0.28 & -0.30 & -0.49 & -0.42 & -0.45 & -0.63 \\
\hline & 250 & -0.36 & -0.38 & -0.41 & -0.50 & -0.53 & -0.58 \\
\hline & 300 & -0.42 & -0.44 & -0.36 & -0.57 & -0.61 & -0.54 \\
\hline & 400 & -0.55 & -0.57 & -0.43 & -0.71 & -0.75 & -0.66 \\
\hline & L 500 & -0.72 & -0.76 & -0.61 & -0.90 & -0.95 & -0.82 \\
\hline
\end{tabular}



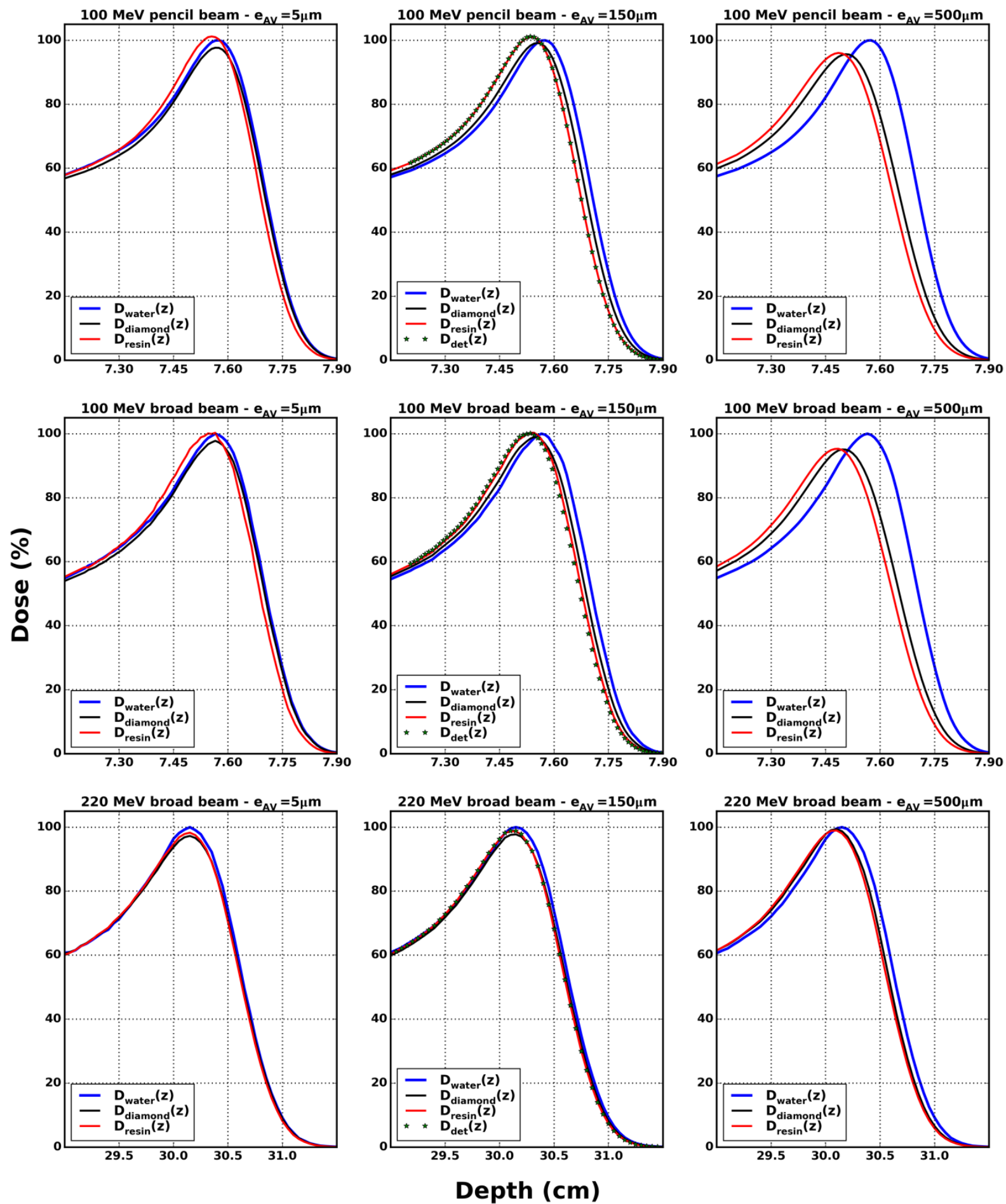

Figure 5: Depth-dose curves calculated by Monte Carlo simulations with an active volume of water $\left(\mathrm{D}_{\text {water }}(\mathrm{z})\right)$, a diamond crystal alone $\left(\mathrm{D}_{\text {diamond }}(\mathrm{z})\right)$, a diamond crystal with the front silver resin $\left(D_{\text {resin }}(z)\right)$, and with the model of the full detector $\left(D_{\text {det }}(z)\right)$.

Regarding all $\mathrm{e}_{\mathrm{AV}}$ reported in Table 2, $\Delta$ Range $_{\mathrm{MC}}$ shows that the position shift of the Bragg peak toward the entrance increases with $\mathrm{e}_{\mathrm{AV}}$, up to $0.76 \mathrm{~mm}$ for $\mathrm{e}_{\mathrm{AV}}$ equal to $500 \mu \mathrm{m}$. According to the results of modeling the diamond crystal alone, no $\mathrm{e}_{\mathrm{AV}}$ can produce a $\mathrm{D}_{\max }$ agreeing with the reference 
within $2 \%$ for the investigated energies and $\mathrm{e}_{\mathrm{AV}}$ range. The Bragg peak dose for the diamond crystal alone is systematically underestimated and depends on the beam energy and the $\mathrm{e}_{\mathrm{Av}}$. This underestimation is consistent with experimental results reported by Cirrone et al (2003) for natural and synthetic single crystal diamonds of $0.3 \mathrm{~mm}$ and $0.4 \mathrm{~mm}$ thicknesses, respectively, as well as by other authors (Onori et al 2000, Pacilio et al 2002, Fidanzio et al 2002) for the PTW 60003. The optimal $\mathrm{e}_{\mathrm{AV}}$ that produces a minimal Bragg peak dose perturbation is about $100 \mu \mathrm{m}$ and $400 \mu \mathrm{m}$ for beam energies of $100 \mathrm{MeV}$ and $220 \mathrm{MeV}$, respectively. Since the dosimeter has to be accurate for all clinical beams at this energy range with only one $\mathrm{e}_{\mathrm{AV}}$ value, an additional element in front of the active volume has been investigated to reduce the energy-dependence of the SCDD-Pro.

10

\subsubsection{Impact of the active volume mass density on depth-dose curves}

Figure 6 shows $D_{\text {water }}, D_{\text {water }}\left[\rho_{\text {diamond }}\right](z)$ and $D_{\text {diamond }}(z)$ for an $e_{A V}$ of $500 \mu \mathrm{m}$ and the $100 \mathrm{MeV}$ pencil beam. No significant difference is observed between $D_{\text {water }}\left[\rho_{\text {diamond }}\right](z)$ and $D_{\text {diamond }}(z)$; showing that the main perturbation is not caused by the atomic composition of the diamond. This result was expected since the variation in the water/carbon mass stopping power ratio is negligible in the proton energy range investigated. Regarding $\Delta_{\text {density }}$ (Figure 6), four regions can been identified: from 0 to $\sim 6 \mathrm{~cm}$ in depth, $\Delta_{\text {density }}$ is nearly zero; from $\sim 6 \mathrm{~cm}$ to $7.43 \mathrm{~cm}$ (denoted by $\mathrm{Z}_{1}$ ), $\Delta_{\text {density }}$ increases; from $\mathrm{Z}_{1}$ to $7.66 \mathrm{~cm}$ (denoted by $\mathrm{Z}_{2}$ ), $\Delta_{\text {density }}$ decreases; and beyond $\mathrm{Z}_{2}, \Delta_{\text {density }}$ tends toward zero.

At the active volume depths of $0, \mathrm{Z}_{1}$ and $\mathrm{Z}_{2}$, the proton ranges are calculated to $77.1,1.99$ and $0.51 \mathrm{~mm}$ for Range $\mathrm{water}\left[\rho_{\mathrm{water}}\right]$, and $21.9,0.56$ and $0.15 \mathrm{~mm}$ for $\operatorname{Range}_{\mathrm{water}}\left[\rho_{\text {diamond }}\right]$. Thus, at the phantom entrance, the Range $\mathrm{water}\left[\rho_{\mathrm{water}}\right]$ and $\operatorname{Range}_{\mathrm{water}}\left[\rho_{\text {diamond }}\right]$ are significantly larger than $\mathrm{e}_{\mathrm{AV}}$. There is no fluence perturbation caused by the crystal thickness and the dose deposited in the active volume is independent from the mass density. If the active volume position increases up to $Z_{1}$, Range $_{\text {water }}\left[\rho_{\text {diamond }}\right]$ becomes similar to $\mathrm{e}_{\mathrm{AV}}$ and all residual proton energy is deposited in the active volume, while Range water $\left[\rho_{\text {water }}\right]$ remains larger than the $\mathrm{e}_{\mathrm{AV}}$. Thus, the $\mathrm{D}_{\text {water }}\left[\rho_{\text {diamond }}\right](\mathrm{z})$ becomes larger than $\mathrm{D}_{\text {water }}(\mathrm{z})$. When the active volume position increases from $\mathrm{Z}_{1}$ to $\mathrm{Z}_{2}$, Range $\left.\mathrm{water}_{\text {water }}\right]$ becomes similar to $\mathrm{e}_{\mathrm{AV}}$ and all proton energy is deposited in the active volume. Thus, the energies deposited in active volume of $\rho_{\text {diamond }}$ and $\rho_{\text {water }}$ mass densities are the same at $Z_{2}$, and $D_{\text {water }}\left[\rho_{\text {diamond }}\right](z)$ is related to $D_{\text {water }}(z)$ by a $\rho_{\text {water }} / \rho_{\text {diamond }}$ factor. After $Z_{2}, \Delta_{\text {density }}$ tends to zero since the residual proton energy tends to zero. 
Therefore, the depth-dose curves perturbation caused by the diamond crystal is mainly explained by the high density of the diamond crystal compared to water.

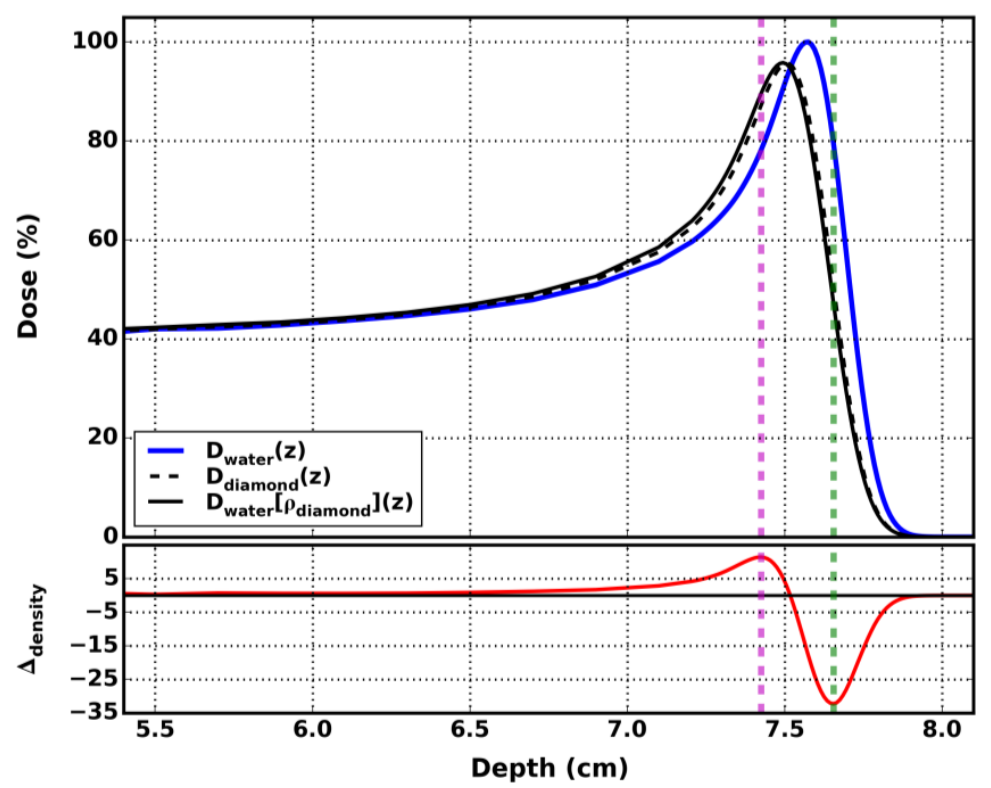

Figure 6: Depth-dose curves calculated in a water active volume of $500 \mu \mathrm{m}$ thickness, a diamond active volume and a water active volume with diamond mass density, for the $100 \mathrm{MeV}$ pencil beam. $\mathrm{Z}_{1}$ and $\mathrm{Z}_{2}$ depths are indicated by the vertical magenta and green dash-lines, respectively.

\subsubsection{Influence of the front silver resin on depth-dose curves}

$\mathrm{D}_{\text {resin }}(\mathrm{z})$ are shown in Figure 5 for the $100 \mathrm{MeV}$ pencil beam, $100 \mathrm{MeV}$ broad beam and $220 \mathrm{MeV}$ broad beam. Only three $\mathrm{e}_{\mathrm{AV}}$ are displayed $(5,150$ and $500 \mu \mathrm{m})$ but all $\Delta \mathrm{Peak}_{\mathrm{MC}}$ and $\Delta$ Range $_{\mathrm{MC}}$ values calculated for the investigated $\mathrm{e}_{\mathrm{AV}}$ are given in Table 2.

Regarding the error on Bragg peak position, $\Delta$ Range $_{\mathrm{MC}}$ increases with the addition of the front silver resin, except for $\mathrm{e}_{\mathrm{AV}}$ below or equal to $100 \mu \mathrm{m}$ for a beam energy of $220 \mathrm{MeV}$, which reduces the error slightly. For $\mathrm{e}_{\mathrm{AV}}$ of $500 \mu \mathrm{m}, \Delta$ Range $_{\mathrm{MC}}$ increases to $0.2 \mathrm{~mm}$ with the front silver resin for all beam energies. For $\mathrm{e}_{\mathrm{AV}}$ of $150 \mu \mathrm{m}, \Delta$ Range $_{\mathrm{MC}}$ changes from $-0.2 \mathrm{~mm}$ to $-0.3 \mathrm{~mm}$ for a beam energy of $100 \mathrm{MeV}$ and remains at $-0.4 \mathrm{~mm}$ at $220 \mathrm{MeV}$. Thus, the Bragg peak position shift caused by a diamond crystal of thickness below or equal to $150 \mu \mathrm{m}$ with front silver resin remains low, with a maximum shift of $0.4 \mathrm{~mm}$ compared to $\mathrm{D}_{\text {water }}(\mathrm{z})$.

Regarding the Bragg peak dose error, the addition of the front silver resin can induce positive $\Delta$ Peak $_{\mathrm{MC}}$ values for $\mathrm{e}_{\mathrm{AV}}$ smaller than $200 \mu \mathrm{m}$ with a beam energy of $100 \mathrm{MeV}$, while only negative values are found for the diamond crystal modeled alone. For the beam energy of $220 \mathrm{MeV}$, only 
negative $\Delta$ Peak $_{M C}$ values are found, but the absolute value of $\Delta$ Peak $_{M C}$ is reduced for $e_{A V}$ smaller than $200 \mu \mathrm{m}$. Regarding all investigated beams, the addition of the front silver resin with $\mathrm{e}_{\mathrm{AV}}$ smaller than or equal to $250 \mu \mathrm{m}$ is found to reduce the error on the Bragg peak dose. Thus, with this additional feature, the perturbation caused by the diamond crystal is partly cancelled.

From the calculation with the modeling of the diamond crystal alone, none of the $\mathrm{e}_{\mathrm{AV}}$ were appropriate because the $\Delta \mathrm{Peak}_{\mathrm{MC}}$ exceeded the $2 \%$ criteria required by the Proton therapy Center of the Curie Institute. With the addition of the front silver resin, the new design perturbation on $\Delta$ Peak $_{\mathrm{MC}}$ is less than $2 \%$ for $\mathrm{e}_{\mathrm{AV}}$ smaller than or equal to $150 \mu \mathrm{m}$. For instance, considering an $\mathrm{e}_{\mathrm{AV}}$ of $150 \mu \mathrm{m}, \Delta$ Peak $_{\mathrm{MC}}$ is $+1.1 \%,+0.3 \%$ and $-1.3 \%$ for the $100 \mathrm{MeV}$ pencil beam, $100 \mathrm{MeV}$ broad beam, and $220 \mathrm{MeV}$ broad beam, respectively.

In accordance with the previous results analysis, the SCDD-Pro was mounted with a synthetic single crystal diamond of $150 \mu \mathrm{m}$ in thickness with an electrical silver resin connection. Smaller $\mathrm{e}_{\mathrm{AV}}$ can show better results than $150 \mu \mathrm{m}$ for some beams, but, for technical reasons, the largest thickness within the $2 \%$ criteria on $\triangle \mathrm{Peak}_{\mathrm{MC}}$ was chosen. Indeed, very small $\mathrm{e}_{\mathrm{AV}}$ may cause an electrical shortcircuit between the two opposite surfaces of the diamond crystal (electrodes were deposited on the entire $1 \times 1 \mathrm{~mm}^{2}$ surfaces).

\subsubsection{Protons energy and fluence perturbations caused by the front silver resin}

Figure 7 shows the depth-dose curve perturbation factors, $\varepsilon_{\Delta \mathrm{E}}$ and $\varepsilon_{\Delta \Phi}$, as a function of depth for the $\mathrm{e}_{\mathrm{AV}}$ of $150 \mu \mathrm{m}$ with the $100 \mathrm{MeV}$ pencil beam. The $\varepsilon_{\Delta \mathrm{E}}$ is always positive and increases slightly with the depth with a maximum value of about 0.05 at Bragg peak position. Thus, the addition of the front silver resin reduces the proton energies entering the active volume and consequently increases the dose deposited in the active volume. According to the $\varepsilon_{\Delta \mathrm{E}}$ values in this simulation, this effect alone could increase the Bragg peak dose up to $5 \%$.

From the water phantom entrance to $7.4 \mathrm{~cm}$ in depth, the $\varepsilon_{\Delta \Phi}$ value is zero, but when the depth becomes greater than $7.4 \mathrm{~cm}$, the $\varepsilon_{\Delta \Phi}$ decreases rapidly. Thus, the addition of the front silver resin does not reduce the fluence for depths from entrance to $7.4 \mathrm{~cm}$. At $7.4 \mathrm{~cm}$, the fluence is slightly reduced but becomes significant only after the Bragg peak position. This effect alone could have decreased the Bragg peak dose and aggravated the perturbation caused by the diamond crystal mass density, but the $\Delta \Phi$ effect occurs after the $\Delta \mathrm{E}$ effect so that the total perturbation (red dash-line on 
Figure 7) can compensate for the negative $\Delta$ Peak values that were found with $\mathrm{D}_{\text {diamond }}(\mathrm{z})$. Thus, the reduction of the Bragg peak dose perturbation with the addition of the front silver resin is explained by the increase of the energy deposition in the active volume due to the slight energy reduction of protons crossing the front silver resin before entering the active volume.

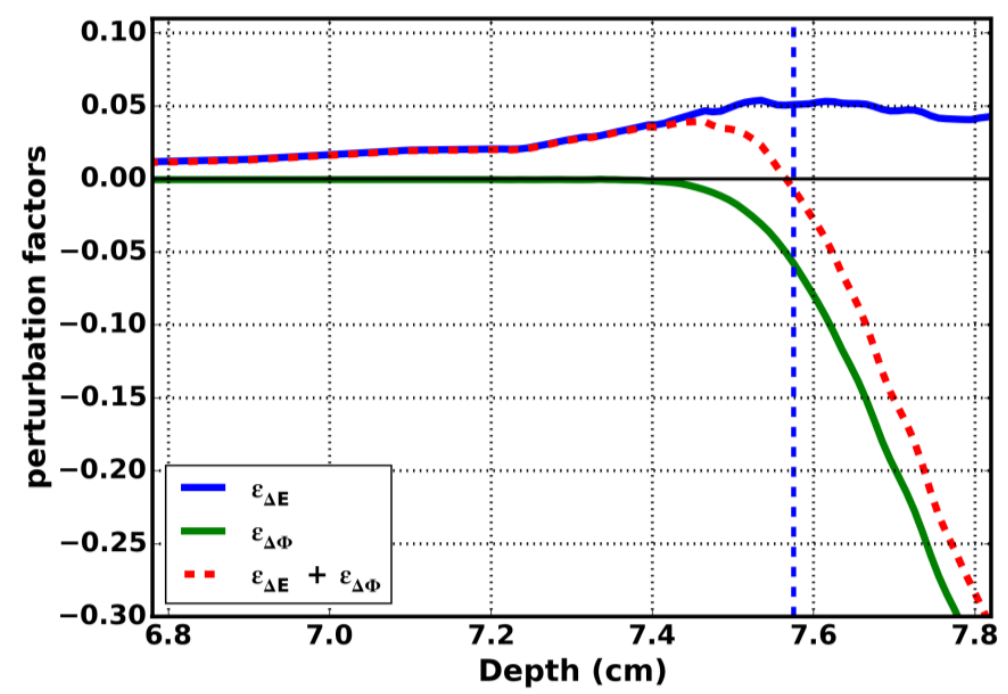

Figure 7: Depth-dose curve perturbation factors, $\varepsilon_{\Delta \mathrm{E}}$ and $\varepsilon_{\Delta \Phi}$, related to the energy and fluence variations due to the addition of the front silver resin. The Bragg peak position, without perturbation, is indicated by the vertical blue dash-line.

\subsubsection{Influence of the full detector design on depth-dose curves}

$\mathrm{D}_{\text {det }}(\mathrm{z})$ are shown in Figure 5 and are very similar to $\mathrm{D}_{\text {resin }}(\mathrm{z})$. The $\Delta$ Peak $_{\mathrm{MC}}$ and $\Delta \operatorname{Range}_{\mathrm{MC}}$ values from the full detector design are given in Table 3. Values from the previous modeling are also summarized in this table.

Table 3: Summary of the Bragg peak dose errors at each step of the detector modeling.

\begin{tabular}{|c|c|c|c|c|c|c|}
\hline \multirow{2}{*}{$\begin{array}{c}\text { Modeling } \\
\text { Beam }\end{array}$} & \multicolumn{2}{|c|}{ diamond crystal alone } & \multicolumn{2}{|c|}{$\begin{array}{l}\text { diamond crystal with } \\
\text { front silver resin }\end{array}$} & \multicolumn{2}{|c|}{ full detector design } \\
\hline & $\begin{array}{c}\Delta \text { Peak }_{\mathrm{MC}} \\
(\%)\end{array}$ & $\begin{array}{c}\Delta \text { Range }_{\mathrm{MC}} \\
(\mathrm{mm})\end{array}$ & $\begin{array}{c}\Delta \text { Peak }_{\mathrm{MC}} \\
(\%)\end{array}$ & $\begin{array}{c}\Delta \text { Range }_{\mathrm{MC}} \\
(\mathrm{mm})\end{array}$ & $\begin{array}{c}\Delta \text { Peak }_{\mathrm{MC}} \\
(\%)\end{array}$ & $\begin{array}{l}\Delta \text { Range }_{\mathrm{MC}} \\
(\mathrm{mm})\end{array}$ \\
\hline $\begin{array}{c}100 \mathrm{MeV} \\
\text { pencil beam }\end{array}$ & -0.7 & -0.19 & +1.1 & -0.32 & +1.2 & -0.35 \\
\hline $\begin{array}{c}100 \mathrm{MeV} \\
\text { broad beam }\end{array}$ & -1.1 & -0.20 & +0.3 & -0.28 & +0.7 & -0.35 \\
\hline $\begin{array}{l}220 \mathrm{MeV} \\
\text { broad beam }\end{array}$ & -2.2 & -0.40 & -1.3 & -0.41 & -1.1 & -0.48 \\
\hline
\end{tabular}


The Plastic Water coating, the epoxy resin, and the aluminum wire connected on the diamond back face (Figure 1), do not perturb the depth-dose curves in proton beams. For the 100-220 MeV energy range, the maximum error on Bragg peak dose with the full detector design is $1.2 \%$ of the Bragg peak dose from $\mathrm{D}_{\text {water }}(\mathrm{z})$. Moreover, if the point of measurement is set at $0.415 \mathrm{~mm}$ in front of the active volume center, i.e. at $1.41 \mathrm{~mm}$ from the detector entrance surface, the error on Range ${ }_{90 \%}$ would be less than $0.065 \mathrm{~mm}$. The agreement between $\mathrm{D}_{\operatorname{det}}(\mathrm{z})$ and $\mathrm{D}_{\text {water }}(\mathrm{z})$ is excellent by using this new effective measurement point with the full detector modeling.

This numerical study shows that the perturbation caused by the full design agrees with the requirements for dose curves estimation of unmodulated clinical proton beams in the $100-220 \mathrm{MeV}$ energy range; in particular, the $2 \%$ error requirement (without correction applied on detector response) is reached for the determination of the Bragg peak dose.

\subsection{Experimental evaluation of the detector response}

\subsubsection{Detector radiography and electrical characterization}

Radiographs of the active volume region for the SCDD-Pro are shown in Figure 8. The coating is made of water-equivalent materials. Only the silver resin and the aluminum wire at the back diamond surface can be distinguished.
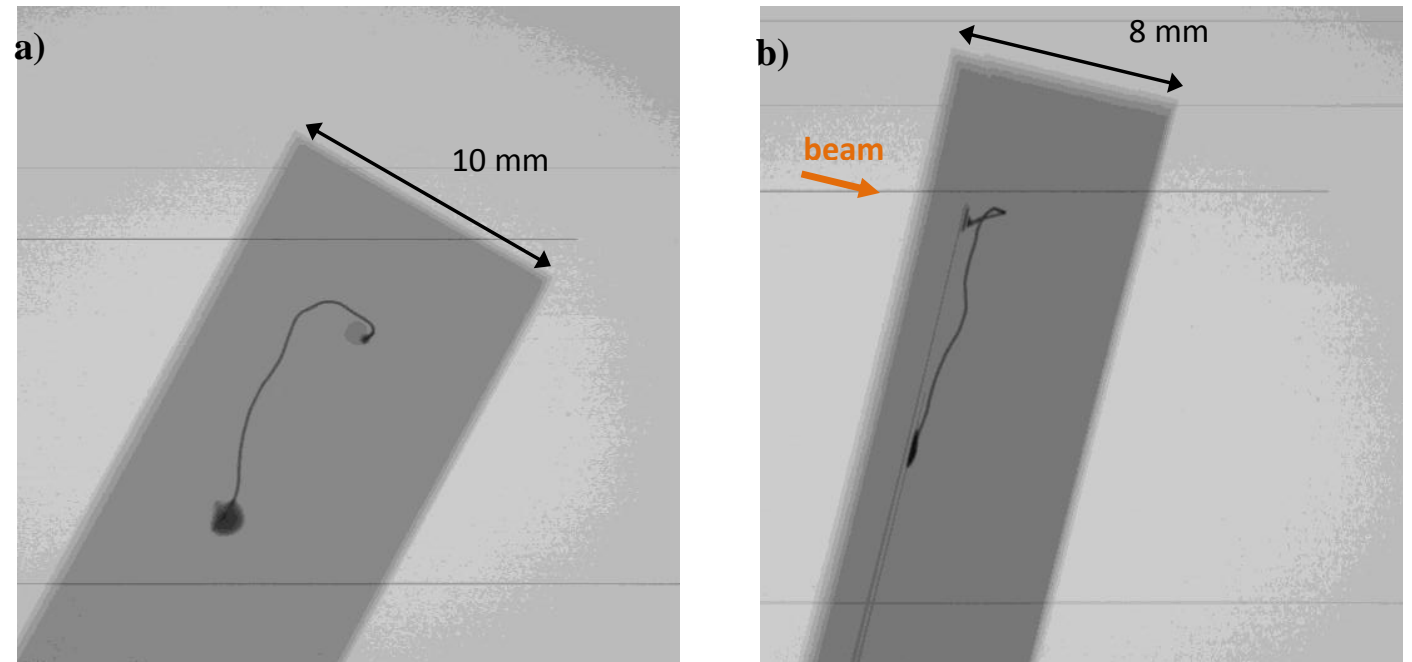

Figure 8: Radiographs of the (a) front view and (b) side view of the SCDD-Pro head. The beam direction is drawn on the side view. 
The current-voltage curve obtained with the SCDD-Pro is shown in Figure 9a from -100 to $+100 \mathrm{~V}$. The current has a symmetrical response to bias voltage with a saturation value of $2.15 \mathrm{nA}$ for positive bias voltage which is reached at $+50 \mathrm{~V}$ with a charge collection efficiency higher than 99\%. Subsequently, the SCDD-Pro could be used from bias equal or above $+50 \mathrm{~V}$ without any differences in the signal observed. In this paper, the SCDD-Pro is used at $+50 \mathrm{~V}$. The current stability with the SCDD-Pro in the $\mathrm{kV}$ photon beam is shown in Figure $\mathbf{9 b}$. The standard deviation of the current reaches $0.51 \mathrm{pA}$ and thus the signal-to-noise ratio is about 4200 . These results confirm the high quality of both the electrical contacts and the synthetic single crystal diamond mounted in the SCDD-Pro.
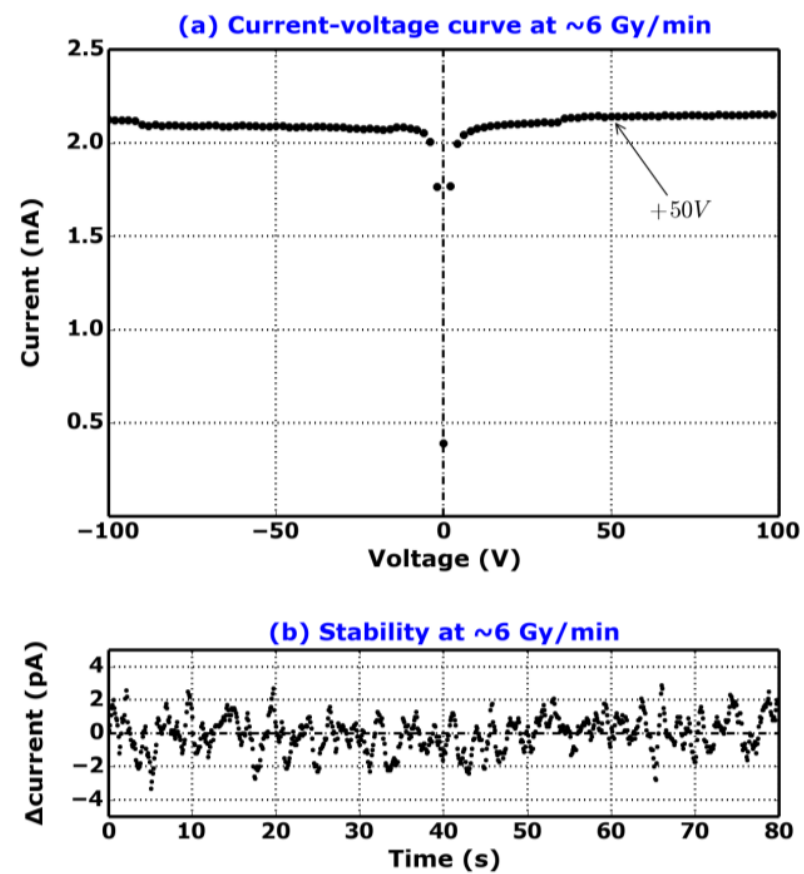

Figure 9: (a) Current-voltage characteristic and (b) current stability at $+50 \mathrm{~V}$ of the SCDD-Pro in a $\mathrm{kV}$ photon beam at a dose rate of $6 \mathrm{~Gy} / \mathrm{min}$.

\subsubsection{Dosimetrical characterization in a modulated clinical proton beam}

Regarding the repeatability (Figure 10b), the mean charge $\mathrm{Q}$ is $21.27 \mathrm{nC}$, the maximum deviation from $\mathrm{Q}$ is $0.23 \%$, and $\sigma(\mathrm{Q})$ is $0.11 \%$ under irradiation with the $\mathrm{m} 138 \mathrm{MeV}$ proton beam. The $\mathrm{Q}_{\mathrm{bck}}$ is estimated at $19 \mathrm{pC}$ (during 27.3 seconds) and thus the SCDD-Pro signal-to-background ratio is about 1100 at $2.2 \mathrm{~Gy} / \mathrm{min}$. Regarding the dose linearity (Figure 10a), the maximum deviation from linearity, for a delivered dose larger than $0.05 \mathrm{~Gy}$, is $0.4 \%$. For a delivered dose of $0.05 \mathrm{~Gy}$, the deviation is $1.0 \%$, but it may be caused by the delivery system uncertainty (at $2.2 \mathrm{~Gy} / \mathrm{min}$, the dose 
of $0.05 \mathrm{~Gy}$ is delivered in 1.4 seconds) or the monitor resolution (the dose uncertainty is $2 \%$ of the expected delivery dose of $0.05 \mathrm{~Gy}$ for a monitor resolution of $0.1 \mathrm{MU}$ ). Regarding the dose rate dependence (Figure 10c), the mean sensitivity is $21.24 \mathrm{nC} / \mathrm{Gy}$ and the maximum sensitivity variation is $0.36 \%$. These results evidence the good signal stability, dose linearity and dose rate independence of the SCDD-Pro under a dose rate of $5.5 \mathrm{~Gy} / \mathrm{min}$.

(a) Dose linearity:

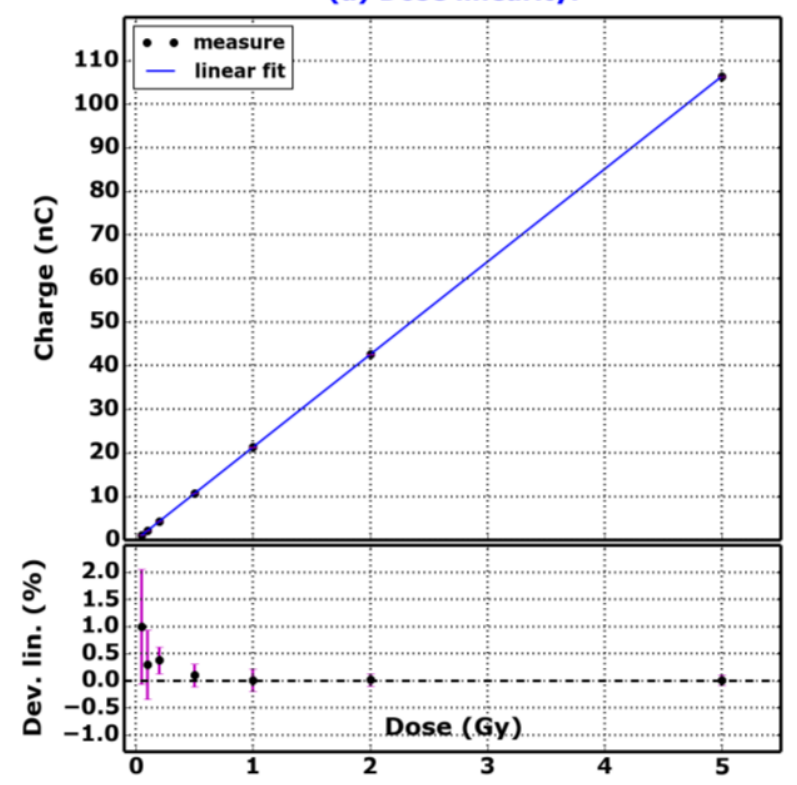

(b) Repeatability:

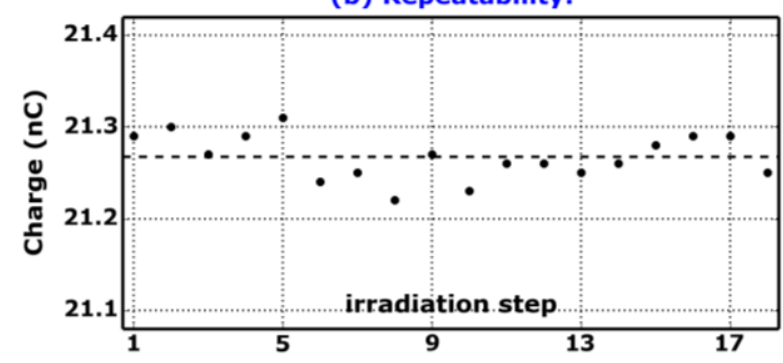

(c) Dose rate dependence:

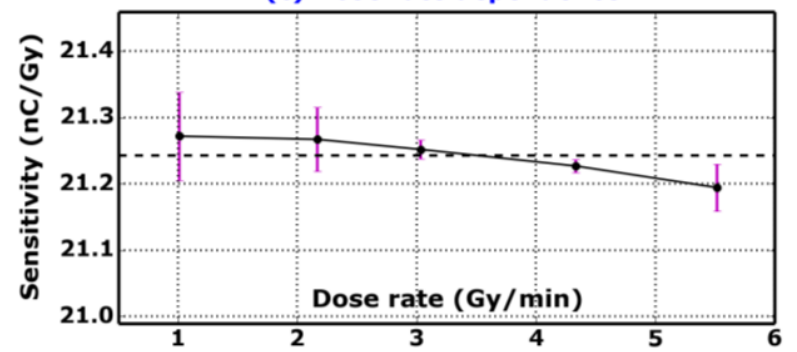

Figure 10: (a) Measured SCDD-Pro charge as a function of the delivered dose and percentage deviation of the measured SCDD-Pro sensitivity with respect to the measured sensitivity at 5.0 Gy. (b) Measured SCDD-Pro charge as a function of consecutive irradiation of $1.0 \mathrm{~Gy}$. The mean value is plotted as a dash-line. (c) Measured SCDD-Pro sensitivity as a function of the dose rate. The mean value is plotted as a dash-line. All the standard deviations are plotted at 2-sigma.

\subsubsection{Depth-dose curves measurement of clinical proton beams}

The depth-dose curves measured with the SCDD-Pro and the reference IBA PPC05 planeparallel ionization chamber are shown in Figure 11. Good agreement between $D_{S C D D-P r o}(z)$ and $\mathrm{D}_{\mathrm{PPC} 05}(\mathrm{z})$ is found with maximum differences of $1.2 \%, 1.6 \%, 0.8 \%$ and $1.6 \%$ calculated for the $163 \mathrm{MeV}, 138 \mathrm{MeV}, 89 \mathrm{MeV}$ and m138 MeV proton beams, respectively.

The differences, $\Delta \mathrm{Peak}_{\mathrm{exp}}, \Delta \mathrm{Width}_{\mathrm{exp}}$ and $\Delta \mathrm{DDF}_{\mathrm{exp}}$, derived from the curves displayed in Figure $\mathbf{1 1}$ are given in Table $\mathbf{4}$ for the unmodulated proton beams. Good agreement is found on $\Delta \mathrm{Peak}_{\exp }$ for the three investigated proton energies, with a maximum deviation of $0.24 \%$ compared to the reference chamber. The SCDD-Pro accuracy on the Bragg peak dose compared to a plane-parallel ionization chamber indicates that the SCDD-Pro has no energy dependence. A small negative 
difference on $\Delta \mathrm{Width}_{\mathrm{exp}}$ and a small positive difference on $\Delta \mathrm{DDF}_{\text {exp }}$ are found for all beam energies investigated. These differences are not significant and may be attributed to the positioning error during detector scanning: the water tank positioning system has an accuracy of $0.1 \mathrm{~mm}$ and the maximum difference on $\Delta \mathrm{Width}_{\mathrm{exp}}$ or $\Delta \mathrm{DDF}_{\mathrm{exp}}$ is about $0.2 \mathrm{~mm}$.
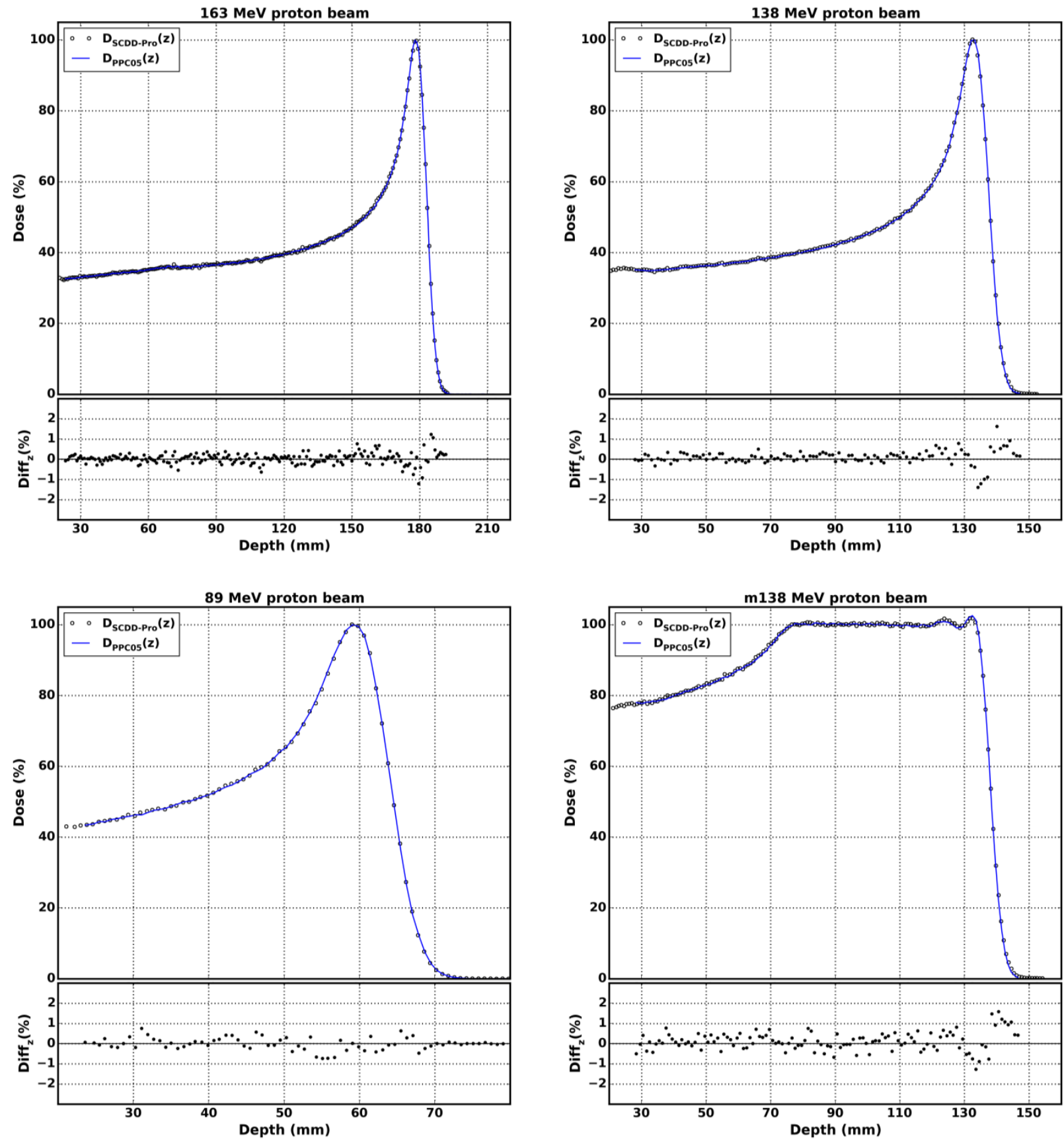

Figure 11: Depth-dose curves measured in a water tank with SCDD-Pro and IBA PPC05. The difference between SCDD-Pro and IBA PPC05 depth-dose curves is plotted under each graph. 
Table 4: Difference of the Bragg peak dose, the width at $80 \%$ and the distal-dose fall-off distance between the curves measured with the SCDD-Pro and the IBA PPC05.

\begin{tabular}{lccccc}
\hline \hline Proton beams & $\begin{array}{c}\Delta \text { Peak }_{\text {exp }} \\
(\%)\end{array}$ & $\begin{array}{c}\text { Width } \\
(\mathrm{mm})\end{array}$ & $\begin{array}{c}\Delta \text { Width }_{\text {exp }} \\
(\mathrm{mm})\end{array}$ & $\begin{array}{c}\mathrm{DDF}_{\mathrm{PPC} 05} \\
(\mathrm{~mm})\end{array}$ & $\begin{array}{c}\Delta \mathrm{DDF}_{\text {exp }} \\
(\mathrm{mm})\end{array}$ \\
\hline $163 \mathrm{MeV}$ & -0.24 & 8.0 & -0.16 & 4.6 & +0.15 \\
$138 \mathrm{MeV}$ & +0.11 & 8.1 & -0.05 & 4.4 & +0.23 \\
$89 \mathrm{MeV}$ & +0.06 & 7.9 & -0.21 & 4.5 & +0.08 \\
\hline \hline
\end{tabular}

Marsolat et al (2016) recently demonstrated the lack of reproducibility of PTW 60019 microDiamond in the 89-138 MeV energy range with four detectors, and have found a discrepancy of up to $6.7 \%$ and $2.2 \mathrm{~mm}$ on $\Delta$ Peak $_{\exp }$, and $\Delta \mathrm{Width}_{\exp }$, respectively. In the current work, the experimental results of the $\mathrm{D}_{\mathrm{SCDD}-\mathrm{Pro}}(\mathrm{z})$ demonstrate that the SCDD-Pro does not perturb the depthdose curve measurements of clinical proton beams. These results are consistent with the numerical optimization of the detector design presented in this paper. Depth-dose curves measured with the SCDD-Pro mounted with a single crystal diamond of $150 \mu \mathrm{m}$ in thickness are at least as good as a synthetic crystal diamond Schottky diode configuration as used in the PTW 60019 microDiamond. Only one SCDD-Pro device has been investigated in this work, but production of synthetic single crystal diamonds is well controlled and their mounting as presented in Figure $\mathbf{1}$ should allow the fabrication of suitable diamond dosimeters with a good reproducibility.

\section{Conclusion}

In this work, the crystal dimensions of a diamond detector have been optimized by Monte Carlo simulations to reduce the dose curve perturbation with proton beams. In particular, the Monte Carlo simulations have shown that the use of a diamond crystal alone cannot achieve accurate depth-dose curves. However, the Monte Carlo simulations have demonstrated that the addition of a silver resin in front of the active volume can compensate for the Bragg peak dose perturbation caused by the diamond crystal, thus allowing more accurate measurement of the depth-dose curves without any correction. A discrepancy in the Bragg peak dose smaller than $1.2 \%$ was found in the proton energy range of $100-220 \mathrm{MeV}$ for the full detector design including a diamond crystal of $150 \mu \mathrm{m}$ in thickness $(1 \mathrm{~mm}$ in width) and a front silver resin of $250 \mu \mathrm{m}$ in thickness. More generally, it was demonstrated that an active volume with higher density than water perturbs the depth-dose curves, 
but the addition of a specific element in front of the active volume can compensate for this perturbation.

Based on these results, an SCDD-Pro prototype has been built and tested in high energy proton beams to evaluate the SCDD-Pro performance in a clinical environment. The SCDD-Pro has demonstrated a stable response with a maximum deviation below $0.23 \%$ from the mean sensitivity. The charge measured as a function of the delivered dose over 0.05 Gy has demonstrated the good linearity response with a maximum deviation of $0.4 \%$. No significant dose rate dependence was measured with a maximum sensitivity variation of $0.36 \%$ in the range between 1.0 and $5.5 \mathrm{~Gy} / \mathrm{min}$.

Finally, the depth-dose curves measured with the SCDD-Pro were compared with those measured with an IBA PPC05 plane-parallel ionization chamber at large field size for several clinical proton beams in the energy range of $89-163 \mathrm{MeV}$. Good agreement was found. For all investigated beams, the differences in the depth-dose curves were below $1.6 \%$ and the deviations in Bragg peak dose were below $0.3 \%$. These good experimental results show that the SCDD-Pro has no energy or dose rate dependence at Bragg peak position and that the SCDD-Pro is suitable for accurate depthdose curve measurements without any correction.

\section{ACKNOWLEDGEMENTS:}

This work was supported by the "DEDIPRO" project which was granted by the French Institute of

Health and Medical Research (INSERM). The authors would like to thank Alexandra Moignier for fruitful discussions, as well as Philippe Bergonzo and Christopher Schneider for proofreading.

\section{REFERENCES:}

Akino Y, Gautam A, Coutinho L, Würfel J and Das I J 2015 Characterization of a new commercial single crystal diamond detector for photon- and proton-beam dosimetry J. Radiat. Res. $56912-8$

Almaviva S, Ciancaglioni I, Consorti R, De Notaristefani F, Manfredotti C, Marinelli M, Milani E, Petrucci A, Prestopino G, Verona C and Verona-Rinati G 2009 Synthetic single crystal diamond dosimeters for Intensity Modulated Radiation Therapy applications Nucl. Instrum. Methods Phys. Res. A 608 191-4 
Almaviva S, Marinelli M, Milani E, Prestopino G, Tucciarone A, Verona C, Verona-Rinati G, Angelone M, Pillon M, Dolbnya I, Sawhney K and Tartoni N 2010 Chemical vapor deposition diamond based multilayered radiation detector: Physical analysis of detection properties J.Appli. Phys. 107014511

Almaviva S, Marinelli M, Milani E, Tucciarone A, Verona-Rinati G, Consorti R, Petrucci A, De Notaristefani F and Ciancaglioni I 2008 Synthetic single crystal diamond diodes for radiotherapy dosimetry Nucl. Instrum. Methods Phys. Res. A 594 273-7

Betzel G T, Lansley S P, Baluti F, Reinisch L and Meyer J 2010 Operating parameters of CVD diamond detectors for radiation dosimetry Nucl. Instrum. Methods Phys. Res. A 614 130-6

Bichsel H 1995 Calculated Bragg curves for ionization chambers of different shapes Med. Phys. 22 $1721-6$

Bouchard H, Kamio Y, Palmans H, Seuntjens J and Duane S 2015b Detector Dose Response in Megavoltage Small Photon Beams. II. Pencil Beam Perturbation Effects Med. Phys. 42 6048-61

Bouchard H, Seuntjens J, Duane S, Kamio Y and Palmans H 2015a Detector Dose Response in Megavoltage Small Photon Beams. I. Theoretical Concepts Med. Phys. 42 6033-47

Brualla-González L, Gómez F, Pombar M and Pardo-Montero J 2016 Dose rate dependence of the PTW 60019 microDiamond detector in high dose-per-pulse pulsed beams Phys. Med. Biol. 61 N11-9

Bucciolini M, Borchi E, Bruzzi M, Casati M, Cirrone P, Cuttone G, De Angelis C, Lovik I, Onori S, Raffaele L and Sciortino S 2005 Diamond dosimetry: Outcomes of the CANDIDO and CONRAD INFN projects Nucl. Instrum. Methods Phys. Res. A 552 189-96

Ciancaglioni I, Marinelli M, Milani E, Prestopino G, Verona C, Verona-Rinati G, Consorti R, Petrucci A and Notaristefani F D 2012 Dosimetric characterization of a synthetic single crystal diamond detector in clinical radiation therapy small photon beams Med. Phys. 39 4493-501

Cirrone G A P, Cuttone G, Rafaele L, Sabini M G, De Angelis C, Onori S, Pacilio M, Bucciolini M, Bruzzi M and Sciortino S 2003 Natural and CVD type diamond detectors as dosimeters in hadrontherapy applications Nuclear Physics B (Proc. Suppl.) 125 179-83

Fidanzio A, Azario L, Angelis C D, Pacilio M, Onori S, Kacperek A and Piermattei A 2002 A correction method for diamond detector signal dependence with proton energy Med. Phys. 29 66975

Garino Y, Giudice A L, Manfredotti C, Marinelli M, Milani E, Tucciarone A and Verona-Rinati G 2006 Performances of homoepitaxial single crystal diamond in diagnostic x-ray dosimetry Appl. Phys. Lett. 88151901 
Gomà C, Marinelli M, Safai S, Verona-Rinati G and Würfel J 2016 The role of a microDiamond detector in the dosimetry of proton pencil beams Z. Med. Phys. 26 88-94

Guerrero M J, Tromson D, Rebisz M, Mer C, Bazin B and Bergonzo P 2004 Requirements for synthetic diamond devices for radiotherapy dosimetry applications Diamond Relat. Mater. 13 2046-51

IAEA (International Atomic Energy Agency) Absorbed dose determination in external beam radiotherapy: An international code of practice for dosimetry based on standards of absorbed dose to water. Technical Report Series No. 398 (IAEA, Vienna, 2000)

ICRU (International Commission on Radiation Units and Measurements) 2007 Prescribing, recording and reporting proton-beam therapy. ICRU Report 78

Karger C P, Jäkel O, Palmans H and Kanai T 2010 Dosimetry for ion beam radiotherapy Phys. Med. Biol. 55 R193-234

Lárraga-Gutiérrez J M, Ballesteros-Zebadúa P, Rodríguez-Ponce M, García-Garduño O A and De la Cruz O O 2015 Properties of a commercial PTW-60019 synthetic diamond detector for the dosimetry of small radiotherapy beams Phys. Med. Biol. $60905-24$

Laub W U and Crilly R 2014 Clinical radiation therapy measurements with a new commercial synthetic single crystal diamond detector J. Appl. Clin. Med. Phys. 154890

Lechner W, Palmans H, Sölkner L, Grochowska P and Georg D 2013 Detector comparison for small field output factor measurements in flattening filter free photon beams Radiother. Oncol. 109 35660

Mancosu P, Reggiori G, Stravato A, Gaudino A, Lobefalo F, Palumbo V, Navarria P, Ascolese A, Picozzi P, Marinelli M, Verona-Rinati G, Tomatis S and Scorsetti M 2015 Evaluation of a synthetic single-crystal diamond detector for relative dosimetry on the Leksell Gamma Knife Perfexion radiosurgery system Med. Phys. 42 5035-41

Mandapaka A K, Ghebremedhin A, Patyal B, Marinelli M, Prestopino G, Verona C and Verona-Rinati G 2013 Evaluation of the dosimetric properties of a synthetic single crystal diamond detector in high energy clinical proton beams Med. Phys. 40121702

Marsolat F, De Marzi L, Patriarca A, Nauraye C, Moignier C, Pomorski M, Moignau F, Heinrich S, Tromson D and Mazal A 2016 Dosimetric characteristics of four PTW microDiamond detectors in high-energy proton beams Phys. Med. Biol.61 6413-29

Marsolat F, Tromson D, Tranchant N, Pomorski M, Bassinet C, Huet C, Derreumaux S, Chea M, Cristina K, Boisserie G, Buchheit I, Marchesi V, Gaudaire-Josset S, Lisbona A, Lazaro D, Hugon R and Bergonzo P 2015 Why diamond dimensions and electrode geometry are crucial for small photon beam dosimetry J. Appli. Phys. 118234507 
Marsolat F, Tromson D, Tranchant N, Pomorski M, Roy M L, Donois M, Moignau F, Ostrowsky A, Carlan L D, Bassinet C, Huet C, Derreumaux S, Chea M, Cristina K, Boisserie G and Bergonzo P 2013 A new single crystal diamond dosimeter for small beam: comparison with different commercial active detectors Phys. Med. Biol. 58 7647-60

Morales J E, Crowe S B, Hill R, Freeman N and Trapp J V 2014 Dosimetry of cone-defined stereotactic radiosurgery fields with a commercial synthetic diamond detector Med. Phys. 41 111702

Onori S, Angelis C D, Fattibene P, Pacilio M, Petetti E, Azario L, Miceli R, Piermattei A, Tonghi L B, Cuttone G and Nigro S L 2000 Dosimetric characterization of silicon and diamond detectors in low-energy proton beams Phys. Med. Biol. 45 3045-58

Pacilio M, Angelis C D, Onori S, Azario L, Fidanzio A, Miceli R, Piermattei A and Kacperek A 2002 Characteristics of silicon and diamond detectors in a $60 \mathrm{MeV}$ proton beam Phys. Med. Biol. 47 N107-12

Pedroni E, Bacher R, Blattmann H, Böhringer T, Coray A, Lomax A, Lin S, Munkel G, Scheib S, Schneider U and Tourovsky A 1995 The $200 \mathrm{MeV}$ proton therapy project at the Paul Scherrer Institute: Conceptual design and practical realization Med. Phys. 22 37-53

Pelowitz D B et al 2011 MCNPX User's Manual, Version 2.7.0 Los Alamos National Laboratory

Ralston A, Tyler M, Liu P, McKenzie D and Suchowerska N 2014 Over-response of synthetic microDiamond detectors in small radiation fields Phys. Med. Biol. 59 5873-81

Rossomme S, Hopfgartner J, Vynckier S and Palmans H 2016 Under response of a PTW-60019 microDiamond detector in the Bragg peak of a $62 \mathrm{MeV} / \mathrm{n}$ carbon ion beam Phys. Med. Biol. 61 4551-63

Schirru F, Kisielewicz K, Nowak T and Marczewska B 2010 Single crystal diamond detector for radiotherapy J. Phys. D: Appl. Phys. 43265101

Stankovskiy A, Kerhoas-Cavata S, Ferrand R, Nauraye C, Demarzi L 2009 Monte Carlo modelling of the treatment line of the Proton Therapy Center in Orsay Phys. Med. Biol. 54 2377-94

Tranchant N, Tromson D, Descamps C, Isambert A, Hamrita H, Bergonzo P and Nesladek M 2008 High mobility single crystal diamond detectors for dosimetry: Application to radiotherapy Diamond Relat. Mater. 17 1297-301

Tromson D, Rebisz-Pomorska M, Tranchant N, Isambert A, Moignau F, Moussier A, Marczewska B and Bergonzo P 2010 Single crystal CVD diamond detector for high resolution dose measurement for IMRT and novel radiation therapy needs Diamond Relat. Mater. 19 1012-6 
Vatnitsky S M, Miller D W, Moyers M F, Levy R P, Schulte R W, Slater J D and Slater J M 1999 Dosimetry techniques for narrow proton beam radiosurgery Phys. Med. Biol. 44 2789-801

Vatnitsky S, Miller D, Siebers J and Moyers M 1995 Application of solid state detectors for dosimetry of therapeutic proton beams Med. Phys. 22 469-73

Venanzio C D, Marinelli M, Milani E, Prestopino G, Verona C, Verona-Rinati G, Falco M D, Bagalà P, Santoni R and Pimpinella M 2013 Characterization of a synthetic single crystal diamond Schottky diode for radiotherapy electron beam dosimetry Med. Phys. $\mathbf{4 0} 021712$

Zani M, Bucciolini M, Casati M, Talamonti C, Marinelli M, Prestopino G, Tonnetti A and VeronaRinati G 2013 A synthetic diamond diode in volumetric modulated arc therapy dosimetry Med. Phys. 40092103 